\title{
Endozoicomonas Are Specific, Facultative Symbionts of Sea Squirts
}

\author{
Lars Schreiber ${ }^{1 *}$, Kasper U. Kjeldsen ${ }^{1}$, Peter Funch ${ }^{2}$, Jeppe Jensen ${ }^{1}$, Matthias Obst ${ }^{3}$, \\ Susanna López-Legentil ${ }^{4}$ and Andreas Schramm ${ }^{1}$ \\ ${ }^{1}$ Department of Bioscience, Center for Geomicrobiology and Section for Microbiology, Aarhus University, Aarhus, Denmark, \\ ${ }^{2}$ Section of Genetics, Ecology and Evolution, Department of Bioscience, Aarhus University, Aarhus, Denmark, ${ }^{3}$ Department \\ of Marine Sciences, University of Gothenburg, Gothenburg, Sweden, ${ }^{4}$ Department of Biology and Marine Biology, Center for \\ Marine Science, University of North Carolina Wilmington, Wilmington NC, USA
}

Ascidians are marine filter feeders and harbor diverse microbiota that can exhibit a high degree of host-specificity. Pharyngeal samples of Scandinavian and Mediterranean ascidians were screened for consistently associated bacteria by culture-dependent and -independent approaches. Representatives of the Endozoicomonas (Gammaproteobacteria, Hahellaceae) clade were detected in the ascidian species Ascidiella aspersa, Ascidiella scabra, Botryllus schlosseri, Ciona intestinalis, Styela clava, and multiple Ascidia/Ascidiella spp. In total, Endozoicomonas was detected in more than half of all specimens screened, and in $25-100 \%$ of the specimens for each species. The retrieved Endozoicomonas $16 S$ rRNA gene sequences formed an ascidian-specific subclade, whose members were detected by fluorescence in situ hybridization (FISH) as extracellular microcolonies in the pharynx. Two strains of the ascidian-specific Endozoicomonas subclade were isolated in pure culture and characterized. Both strains are chemoorganoheterotrophs and grow on mucin (a mucus glycoprotein). The strains tested negative for cytotoxic or antibacterial activity. Based on these observations, we propose ascidian-associated Endozoicomonas to be commensals, living off the mucus continuously secreted into the pharynx. Members of the ascidian-specific Endozoicomonas subclade were also detected in seawater from the Scandinavian sampling site, which suggests acquisition of the symbionts by horizontal transmission. The combined results indicate a host-specific, yet facultative symbiosis between ascidians and Endozoicomonas.

Keywords: tunicates, sea squirts, ascidians, Endozoicomonas, symbiosis, mucin, marine

\section{INTRODUCTION}

Several species of ascidians (Tunicata, Ascidiacea), commonly referred to as sea squirts, have been shown to produce bioactive secondary metabolites (Faulkner, 2002), which are hypothesized to protect from biofouling and predation (e.g., Degnan et al., 1989; Paul et al., 1990; Fu et al., 1998; Vervoort et al., 1998; López-Legentil et al., 2006). At least in the case of the ascidian Lissoclinum patella, it was shown that these bioactive compounds are in fact produced by its bacterial symbiont Prochloron didemni (Lewin, 1981; Schmidt et al., 2005). The detection of defensive microbial symbionts in other marine invertebrates, such as corals, sponges and bryozoans (Faulkner, 2002), as well as the potential to use the produced bioactive compounds as anticancer drugs (Simmons et al., 2005; Erwin et al., 2010) has sparked an increased interest for bacterial symbionts of ascidians. The known diversity of 
ascidian-associated bacteria comprises members of several phyla including Actinobacteria, Bacteroidetes, Cyanobacteria, and Firmicutes, as well as Alpha-, Gamma-, and Delta-proteobacteria (Schuett et al., 2005; Martínez-García et al., 2007, 2010; Tait et al., 2007; Erwin et al., 2012, 2014; Dishaw et al., 2014; Tianero et al., 2014; López-Legentil et al., 2015b, 2016).

Ascidians are filter feeders and can pump tens of liters of water through their bodies per day (Petersen and Riisgård, 1992). Water enters through the buccal siphon, passes through a perforated and ciliated pharynx covered with a mucus-net that is produced continuously and traps minute food particles down to the micrometer range, before it leaves through the atrial siphon (MacGinitie, 1939; Bone et al., 2003). The mucus net together with entrapped food particles is eventually transported to the ascidian gut for digestion (MacGinitie, 1939). To our knowledge, microbiomes of ascidian pharynges have so far only been explored by a single study (Moss et al., 2003), while most other studies focused on the tunic (Schuett et al., 2005; MartínezGarcía et al., 2007, 2010; Tait et al., 2007; Erwin et al., 2012, 2014; López-Legentil et al., 2015a,b), the gonads (Tait et al., 2007; Erwin et al., 2012), or the gut (Dishaw et al., 2014). However, in contrast to the tunic, which is constantly exposed to the external environment, or the gonads and gut, which are located relatively secluded within the visceral cavity, the pharynx appears to be a well-suited habitat for bacterial symbionts: (i) it offers protection by being located within the ascidian body, and (ii) the large flow of seawater through the pharynx offers a constant supply of nutrients.

We aimed to explore the bacterial diversity associated with the pharynx tissue of ascidians in order to identify potential symbiotic lineages. The term "symbiosis" is here used in its broadest sense as the "living together of unlike organisms" (sensu De Bary, 1879) and thus encompasses mutualism (the fitness of both organisms is improved), commensalism (one organism's fitness is improved with no negative effect on the fitness of the other), and parasitism (one organism's fitness is improved while the fitness of the other is negatively affected). The frequent recovery of sequences affiliated with the Endozoicomonas clade (Gammaproteobacteria, Hahellaceae) indicated a symbiosis between Endozoicomonas and ascidians, and consequently led us to specifically focus on these bacteria. The aims of this study were thus (i) to test if Endozoicomonas are generally and specifically associated with ascidians, and (ii) to investigate the interaction between Endozoicomonas and ascidians. These aims were pursued using Scandinavian and Mediterranean ascidian specimens and a combination of culture-dependent and -independent approaches.

\section{MATERIALS AND METHODS}

\section{Sample Collection and Identification}

Specimens of the ascidian genera Ascidia and Ascidiella, as well as of the species Botryllus schlosseri, Ciona intestinalis, and Styela clava were collected from Gullmarsfjorden, Sweden, and from Limfjorden, Denmark (Figure S1), between September 2009 and October 2011. Three A. aspersa specimens were collected along the Mediterranean coast of Spain (Figure S1) in January/February 2013. Detailed metadata of all sampled specimens are listed in Table S1. Ascidian species were identified using both morphological (Lützen, 1967; Turon, 1987) and molecular approaches (see below).

Specimens BS-1 to BS-6 of the colonial ascidian $B$. schlosseri (where zooids share a single tunic) were sampled as whole animals. Specimens AJ-1 to AJ-4 were too small for dissection and were also processed as whole animals. Whole animals were rinsed with sterile seawater before DNA extraction. All remaining ascidian specimens were dissected. Their pharynx tissues were removed and rinsed with sterile water or seawater to remove cross-contamination from seawater. Due to the small size of specimen AA-15, gut, and pharynx of this animal could not be separated and were sampled together. The sizes of the remaining dissected specimens made cross-contamination of the sampled pharynx tissues with other tissue types very unlikely. The DNA of whole animals or pharynx tissues, respectively, was extracted with the DNeasy Blood and Tissue Kit (Qiagen, Venlo, The Netherlands). This extracted DNA was the basis for ascidian species identification and for identifying ascidian-associated bacteria.

For taxonomic identification of specimens a fragment of the mitochondrial cytochrome c oxidase I gene (CO1) was amplified with primers LCO1490f and HCO2198R (Folmer et al., 1994). PCR products were re-amplified if the initial PCR yielded insufficient material for downstream analysis. PCR products of samples AV-10, AS-1, BS-1, CI-5, and SC-4 (Table S1) were purified with the Wizard ${ }^{\circledR}$ SV Gel and PCR CleanUp System (Promega, Fitchberg, USA) and cloned using the pGEM $^{\circledR}$-T vector System (Promega) prior to Sanger sequencing. PCR products of all other samples were sequenced directly. All sequencing was performed by Macrogen Inc. (Seoul, South Korea).

CO1 sequences were aligned using ClustalW (Larkin et al., 2007) implemented in Geneious v5.6.3 (created by Biomatters; available from http://www.geneious.com) with the following parameters: gap opening cost 24 and gap extension cost 12 . Final alignment positions of CO1 gene sequences were 589 bp for C. intestinalis and $586 \mathrm{bp}$ for all other ascidians. Neighbour-joining (NJ) analysis was conducted in MEGA 5 (Tamura et al., 2011) using the Jukes-Cantor model of nucleotide substitution and 10,000 bootstrap replicates (Felsenstein, 1985). The software JModelTest2 (Guindon and Gascuel, 2003; Darriba et al., 2012) was used to select the best model of DNA substitution for maximum likelihood (ML) analysis according to the Akaike information criterion (AIC). The transitional model TIM3 $+\mathrm{I}+\mathrm{G}$ with substitution rates varying among sites according to an invariant gamma distribution was subsequently selected. Maximum likelihood analysis was conducted using the phangorn package for R (Schliep, 2011) using 1000 bootstrap replicates.

\section{PCR-Based Survey of Bacteria Associated With the Pharynx Tissue of Ascidians}

Bacterial 16S rRNA genes were amplified with primer sets 26F/1492R (Hicks et al., 1992; Muyzer et al., 1995; specimens AA1 to AA-4, AA-12, AM-1, AM-2, AV-1, AV-12, AS-5, BS-2, and 
CI-2) and GM1F/Bac1075R (Muyzer et al., 1993; Ohkuma and Kudo, 1998; specimens AA-14 to AA-16). HotStar Taq Master Mix (Qiagen) and the following PCR conditions were used for primer set 26f/1492R: initial denaturing at $95^{\circ} \mathrm{C}$ for $15 \mathrm{~min} ; 32$ cycles at $92^{\circ} \mathrm{C}$ for $0.5 \mathrm{~min}$, at the annealing temperature for $1 \mathrm{~min}$, and $72^{\circ} \mathrm{C}$ for $1.5 \mathrm{~min}$; final elongation at $72^{\circ} \mathrm{C}$ for 10 min. The annealing temperature was optimized for each sample using separate PCR reactions and varied between 52 and $57^{\circ} \mathrm{C}$. For primer set GM1F/Bac1075R, Taq DNA Polymerase Master Mix RED (Ampliqon, Odense, Denmark) and the following PCR conditions were used: initial denaturing at $95^{\circ} \mathrm{C}$ for $5 \mathrm{~min} ; 27$ cycles at $93^{\circ} \mathrm{C}$ for $45 \mathrm{~s}, 57^{\circ} \mathrm{C}$ for $45 \mathrm{~s}$, and $72^{\circ} \mathrm{C}$ for $1 \mathrm{~min}$; final elongation at $72^{\circ} \mathrm{C}$ for $10 \mathrm{~min}$. PCR products were cloned using the PGEM $^{\circledR}$-T vector System (Promega) and subsequently sequenced from one direction by Macrogen Inc. This yielded partial 16S rRNA gene sequences between 257 and 1178 bp in length. Endozoicomonas sequences of specimens AA-2, AA-3, AM-2, and AV-1 were sequenced to full length and assembled using Sequencher version 5.0.1 (Gene Codes, Ann Arbor, USA). Sequences were taxonomically classified with the ARB software package (Ludwig et al., 2004) based on the SILVA database, Release Ref NR 104 (Quast et al., 2013).

\section{Culture-Based Survey}

Pharynx tissue of A. aspersa (AS-1), A. scabra (AS-2), Ascidia sp. (AM-5, AV-11), and Ascidiella sp. (AV-10) specimens were dissected and washed with filter-sterilized (pore size: 0.2 $\mu \mathrm{m}$ ) seawater. Tissue samples were added to $50 \mu \mathrm{L}$ sterile seawater and homogenized in $1.5 \mathrm{~mL}$ tubes using sterile polypropylene pestles. The homogenate was diluted 1:14 with sterile seawater and $80 \mu \mathrm{L}$ aliquots of this suspension were spread on full and half-strength Difco marine agar plates (BD, Franklin Lakes, USA). Plates were incubated in the dark at either $4,10,15$, or $22^{\circ} \mathrm{C}$ for 1 week and regularly checked for growth. Colonies with unique morphologies were purified by repeated streaking. Isolated strains were preserved at $-80^{\circ} \mathrm{C}$ in marine broth supplemented with glycerol (30\% final concentration).

Strains were identified by $16 \mathrm{~S}$ rRNA gene sequencing: Single colonies were suspended in $100 \mu \mathrm{L}$ PCR-grade $\mathrm{H}_{2} \mathrm{O}$. Of this suspension, $1 \mu \mathrm{L}$ was used as template for PCR with primers GM3 and GM4 (Muyzer et al., 1995). HotStar Taq Master Mix (Qiagen) and the following conditions were used for PCR amplification: initial denaturing at $95^{\circ} \mathrm{C}$ for $5 \mathrm{~min}$; 36 cycles at $95^{\circ} \mathrm{C}$ for $1 \mathrm{~min}, 42^{\circ} \mathrm{C}$ for $1 \mathrm{~min}$, and $72^{\circ} \mathrm{C}$ for $3 \mathrm{~min}$; final elongation at $72^{\circ} \mathrm{C}$ for $10 \mathrm{~min}$. PCR products were directly sequenced (Macrogen Inc.) using either the internal primer $341 \mathrm{~F}$ (strains from specimens AM-5, AS-1, and AV-10)(Muyzer et al., 1993) or the primer set GM3/GM4 (strains from specimen AV-11). PCR products of two obtained Endozoicomonas strains (AVMART05 and KASP37) were cloned and sequenced using the vector primers M13F and M13R. Sequences were assembled using Sequencher version 5.0.1 (Gene Codes). Sequences were trimmed using the online SINA aligner of SILVA (Quast et al., 2013), which removed all bases at either sequence end that could not be aligned. Final 16S rRNA gene fragment lengths were: 616-936 bp for strains originating from specimens AM-5, AS-1, and AV-10; 948-1426 bp for strains originating from specimen AV-11; and 1501-1521 for strains AVMART05 and KASP37. Trimmed sequences were classified based on the best BLASTn hit (Camacho et al., 2009) against NCBI's database of 16S rRNA genes of described microbial species (release December 4th, 2015).

\section{Phylogenetic Analysis of the Endozoicomonas Clade}

Reference 16S rRNA gene sequences affiliated with the Endozoicomonas-containing Hahellaceae family and with a sequence length of $\geq 1400$ bp were retrieved from the SILVA SSU database release 123 (Quast et al., 2013). Nearly fulllength Endozoicomonas 16S rRNA gene sequences generated in this study were aligned using SINA (Pruesse et al., 2012). Members of the Endozoicomonas clade can harbor multiple divergent paralogs of the 16S rRNA gene (this study; Figure S2). Phylogenetic analysis was restricted to the dominant paralog present in public databases, i.e., the paralog-1-type (Figure S2), which represented 827 out of the total 1216 Endozoicomonas sequences inspected in this study. Together with Hahellaceae sequences clustering outside the Endozoicomonas clade, the analyzed dataset comprised a total of 852 sequences. Sequences were aligned de novo using MAFFT-qinsi version 7.221, which also considers the secondary structure of RNA (Katoh et al., 2005). The final alignment contained 1659 sites. Phylogenies were reconstructed using $\mathrm{ML}$, maximum parsimony (MP), and Bayesian inference (BI) approaches. ML analysis was performed as implemented in RAxML version 7.4.2 (Stamatakis et al., 2008) using the General Time Reversible (GTR; Tavaré, 1986) model of nucleotide substitution under the $\Gamma$ model of rate heterogeneity (Yang, 1994, 1996). Maximum parsimony analysis was performed using the PHYLIP software package (version 3.69; Felsenstein, 2005). Node stability of ML and MP phylogenies was evaluated by 1000 bootstrap replicates. Bayesian inference-based analysis was performed using MrBayes 3.2.5 (Ronquist and Huelsenbeck, 2003). MrBayes was run for 2 million generations and trees were sampled every 1000 generations after a burn-in of $25 \%$. Resulting tree topologies were compared using the relative Robinson-Foulds metric (Robinson and Foulds, 1981) as implemented in RAxML. A strict consensus tree summarizing ML, MP, and BI trees was calculated using the consense tool of PHYLIP, and annotated and visualized using the ARB software package (Ludwig et al., 2004). Obtained partial Endozoicomonas sequences were tested for affiliation with the ascidian-specific subclade based on the calculated BI phylogeny and using the Naïve Bayesian method (Wang et al., 2007) as implemented in the classify.seqs command of Mothur version 1.25 (Schloss et al., 2009). For classification, 1000 iterations and a confidence score threshold of $80 \%$ were used. Sequences of the paralog-2-type (Figure S2) were removed prior to analysis.

\section{Endozoicomonas-Specific Screening}

Ascidians and four water samples from the Gullmarsfjord sampling site (Table S1) were screened for bacteria affiliating with the Endozoicomonas clade by semi-specific PCR using primers 
GM1F (Muyzer et al., 1993) and ENDO-1240R (AAC CGT CTG TAT GCA CCA; for further details see section below on Endozoicomonas-specific probe design).

Water samples $(0.5 \mathrm{~L})$ were collected onto polycarbonate filters (pore size: $0.2 \mu \mathrm{m}$ ) and extracted using the PowerLyzer PowerSoil DNA Isolation Kit (MOBIO Laboratories Inc., Carlsbad, USA) prior to PCR. The following PCR conditions were used: initial denaturing at $95^{\circ} \mathrm{C}$ for $15 \mathrm{~min} ; 30$ cycles at $92^{\circ} \mathrm{C}$ for $30 \mathrm{~s}, 52^{\circ} \mathrm{C}$ for $1 \mathrm{~min}$, and $72^{\circ} \mathrm{C}$ for $1.5 \mathrm{~min}$; final elongation at $72^{\circ} \mathrm{C}$ for $10 \mathrm{~min}$. For the majority of specimens and the water samples, PCR products were cloned and sequenced as described above. Instead of cloning, PCR products of specimens AM-4, AA7, and AA-11 were separated by denaturing gel electrophoresis (DGGE) as follows: PCR products were re-amplified with the primer set 341F-GC/907R (Lane, 1991; Muyzer et al., 1993) using the following PCR conditions: initial denaturing at $95^{\circ} \mathrm{C}$ for $15 \mathrm{~min}$; 30 cycles at $92^{\circ} \mathrm{C}$ for $30 \mathrm{~s}, 55^{\circ} \mathrm{C}$ for $1 \mathrm{~min}$, and $72^{\circ} \mathrm{C}$ for $1.5 \mathrm{~min}$; final elongation step at $72^{\circ} \mathrm{C}$ for 10 min. The resulting PCR products were separated by DGGE on polyacrylamide gels containing a gradient of 20-80\% denaturant; $100 \%$ denaturant was $7 \mathrm{M}$ urea and $40 \%$ (v/v) deionized formamide (BioRad, Hercules, USA). The gels were cast and run as described earlier (Nicolaisen and Ramsing, 2002), and stained in $1 \times$ SYBR Gold (Molecular Probes, Leiden, Netherlands) solution. Resulting DGGE bands were excised for subsequent sequencing. All excised bands were re-amplified by PCR with the primer set $341 \mathrm{~F} / 907 \mathrm{R}$, and subsequently sequenced directly by Macrogen Inc.

\section{Endozoicomonas Distribution and Prevalence Data from Previous Publications}

Pyrosequencing 16S rRNA gene sequence data of previous studies targeting the bacterial diversity of several ascidian species (Erwin et al., 2012, 2014; Tianero et al., 2014; LópezLegentil et al., 2016) were re-analyzed to obtain additional data on the prevalence of Endozoicomonas in ascidians. Data was quality trimmed using the prinseq-lite.pl script (Schmieder and Edwards, 2011) and subsequently pre-screened using Mothur 1.36.1 (Schloss et al., 2009) in combination with sequences and taxonomy classification of the "All-Species Living Tree" Project (LTP) database release 119 (Yarza et al., 2008). Data of specimens with a significant proportion of Hahellaceae-affiliated sequences were cleaned of eukaryotic sequences and analyzed thoroughly using the SILVAngs pipeline (Quast et al., 2013). Overall, operational taxonomic units with an abundance of $<1 \%$ were classified as absent (Degnan and Ochman, 2012). Additionally, Endozoicomonas 16S rRNA gene sequences of DGGE data (FJ659121, FJ659156) and of PCR amplicon libraries (DQ884160, DQ884169, DQ884170) from Martínez-García et al. (2007, 2010), as well as data from Tait et al. (2007), and LópezLegentil et al. (2015a) were identified based on their taxonomic classification in the SILVA SSU database release 123 (Quast et al., 2013).

\section{Design, Evaluation, and Optimization of Probes Specific for Ascidian-Associated Endozoicomonas}

Two oligonucleotide probes targeting ascidian-derived Endozoicomonas 16S rRNA gene sequences were designed using the ARB probe tool (Ludwig et al., 2004): probe ENDO-580 (name according to Alm et al. (1996): S-*-Endo-0580-a-A-18; probe sequence $\left[5^{\prime}-3^{\prime}\right]$ : CAA CTT AAG TAG CCG CCT), and probe ENDO-1240 (S-*-Endo-1240-a-A-18; AAC CGT CTG TAT GCA CCA). Specificity of the probes was tested in silico using TestProbe 3.0 and the SILVA database release 123, as implemented on the SILVA website (Quast et al., 2013). Besides Endozoicomonas 16S rRNA genes, probe ENDO-580 targets also a small fraction of sequences $(0.16 \%)$ within the Legionellales. Probe ENDO-1240 also targets sequences within the Rhodospirillales (0.06\%), Sphingomonadales (0.01\%), Thiotrichales (0.06\%), and Vibrionales (0.04\%). Sensitivity of the probes was evaluated in silico using the ARB software package (Ludwig et al., 2004) based on the Endozoicomonas phylogeny reconstructed in this study. Probe ENDO-580 targets 99\% of the sequences affiliated with the ascidian-specific Endozoicomonas subclade. Almost all other Endozoicomonas sequences have 1-3 mismatches to the probe sequence. Probe ENDO-1240 targets $91 \%$ of the sequences affiliated with the ascidian-specific Endozoicomonas subclade and $27 \%$ of the Endozoicomonas sequences outside this subclade. In situ specificity and optimal hybridization conditions of the probes were evaluated using an Endozoicomonas strain isolated in this study whose $16 \mathrm{~S}$ rRNA gene matches both probes perfectly (strain AVMART05; Table S2). Endozoicomonas elysicola DSM 22380 and Lewinella nigricans DSM 23189 were used as one-mismatch-controls for ENDO-580 or ENDO-1240, respectively. Fluorescence in situ hybridization (FISH) with Cy3-labeled oligonucleotide probes (Biomers.net, Ulm/Donau, Germany) was performed as described earlier (Fuchs et al., 2007) with a series of formamide concentrations: $0 \%$, and 10 to $55 \%$ (in 5\% steps). When used with helper probes (Fuchs et al., 2000), hENDO-559 (S-* Endo-0559-a-A-21; CAC GCT TTA CGC CCA GTA ATT) and hENDO-604 (S-*-Endo-0604-a-A-21; GGT TGA GCC CGG GGC TTT CAC), probe ENDO-580 showed good signal intensity and single mismatch discrimination in hybridizations with $35 \%$ formamide. Signal intensity of probe ENDO-1240 was good in hybridizations with up to $35 \%$ formamide. However, single mismatch discrimination was not achieved at these conditions.

\section{Fluorescence in Situ Hybridization}

Dissected pharynx tissue of specimens AA-14 (A. aspersa), AS5 (A. scabra), and AV-12 (Ascidia sp.) were washed in sterilefiltered seawater and fixed in $2 \%$ paraformaldehyde solution for $1 \mathrm{~h}$ at room temperature. Tissue sections were consecutively washed in PBS $\left(130 \mathrm{mM} \mathrm{NaCl}, 10 \mathrm{mM} \mathrm{Na} \mathrm{HPO}_{4} / \mathrm{NaH}_{2} \mathrm{PO}_{4}\right.$; $\mathrm{pH}$ 7.4) and MilliQ, dried onto Superfrost ${ }^{\mathrm{TM}}$ Plus microscope slides (ThermoFisher Scientific, Waltham, USA), dehydrated in an ethanol series $(50 \%, 70 \%, 96 \% ; 3$ min each), and stored 
at $-20^{\circ} \mathrm{C}$. Prior to FISH, tissue sections were circled with a hydrophobic PAP-pen (Kisker Biotech, Steinfurt, Germany) to create "hybridization wells." To saturate unspecific binding sites of the sticky pharynx tissue, the sections were prehybridized at $46^{\circ} \mathrm{C}$ with hybridization buffer containing $35 \%$ formamide $(\mathrm{v} / \mathrm{v}), 0.1 \%$ bovine serum albumin, $200 \mu \mathrm{g} \mathrm{mL}{ }^{-1}$ salmon sperm DNA (Sigma-Aldrich, St. Louis, USA), 1\% blocking reagent (Roche, Basel, Switzerland), $0.9 \mathrm{M} \mathrm{NaCl}, 20$ $\mathrm{mM}$ Tris- $\mathrm{HCl}(\mathrm{pH} 8)$, and $10 \mathrm{mM}$ sodium dodecyl sulfate. FITC-, CY3-, or CY5-labeled oligonucleotide probes (final concentration, $1 \mathrm{pmol} \mu \mathrm{L}^{-1}$; Biomers.net) were added after 2 $\mathrm{h}$, and hybridization proceeded for $90-120 \mathrm{~min}$ at $46^{\circ} \mathrm{C}$. Slides were washed for $15 \mathrm{~min}$ in $50 \mathrm{~mL}$ pre-heated standard washing buffer (Fuchs et al., 2007) at $48^{\circ} \mathrm{C}$, rinsed with MilliQ water, counterstained with 4,6-diamidino-2-phenylindole (DAPI) and mounted in a 4:1 mix of Citifluor (Citifluor Ltd., London, UK) and Vecta Shield (Vector Laboratories Inc., Burlingame, USA). Hybridized samples were examined and imaged with an epifluorescence microscope (Axiovert 200M; Carl Zeiss, Jena, Germany). Additional micrographs were obtained by confocal laser scanning microscopy (LSM700; Carl Zeiss).

\section{Functional Analysis of Endozoicomonas Isolates}

A diffusion assay and an agar overlay assay were used to test for antibacterial activity of the Endozoicomonas isolates against gram-negative (Escherichia coli K-12 JM109) and gram-positive (Bacillus cereus ATCC 10987 and Staphylococcus epidermidis DSM 20044) indicator strains. For the diffusion assay, the isolates were grown in $50 \mathrm{~mL}$ marine broth in $250 \mathrm{ml}$ Erlenmeyer flasks at $28^{\circ} \mathrm{C}$ and $100 \mathrm{rpm}$ for 14 days. Twice a week, $1 \mathrm{~mL}$ of the culture was sampled and centrifuged at $13,400 \mathrm{~g}$ for $5 \mathrm{~min}$ to obtain a cell-free supernatant. The supernatant was sterile-filtered (pore diameter $0.22 \mu \mathrm{m}$ ) and stored at $4^{\circ} \mathrm{C}$ until used. LB plates were inoculated with $100 \mu \mathrm{L}$ of a 1:50 dilution of an overnight culture of the indicator strain using sterile glass beads. Sterile paper discs ( $5 \mathrm{~mm}$ diameter) were placed onto the agar. Then, $15 \mu \mathrm{L}$ cellfree supernatant, marine broth as negative control, or ampicillin solution $\left(100 \mu \mathrm{g} \mathrm{mL}^{-1}\right)$ as a positive control were applied to the paper discs. The plates were incubated for $24 \mathrm{~h}$ at $37^{\circ} \mathrm{C}$ and subsequently checked for zones of inhibition around the paper discs. For the agar overlay assay, $5 \mu \mathrm{L}$ of test strain stock culture was spotted onto a marine agar plate and incubated at $28^{\circ} \mathrm{C}$ until the culture was approx. $0.5-1 \mathrm{~cm}$ in diameter $(2-3$ days). The cultures were then overlaid with $10 \mathrm{~mL}$ of LB agar inoculated with a fresh culture of indicator strain $(200 \mu \mathrm{L}$ of fresh overnight culture in $20 \mathrm{~mL}$ of $40^{\circ} \mathrm{C}$-warm LB agar). The plates were incubated for $24 \mathrm{~h}$ at $37^{\circ} \mathrm{C}$ and subsequently checked for zones of inhibition.

Hemolytic activity was used as a predictor for cytotoxic activity (Gandhi and Cherian, 2000). It was tested by overlaying $5 \%$ sheep blood agar plates with marine agar. Freshly grown liquid cultures of the test strains $(5 \mu \mathrm{L})$ were transferred onto the marine agar phase. The hemolytic test plates were incubated at $28^{\circ} \mathrm{C}$ for 4 days and regularly checked for clearing zones around the colonies. A beta-hemolytic Vibrio splendidus strain isolated from Ascidia sp. (specimen AM-5) was used as a positive control.

DNase activity was tested by overlaying methyl-green (SigmaAldrich) containing DNase test agar (Sigma-Aldrich; Smith et al., 1969) with marine agar. The plates were inoculated by streaking the test strain, incubated at $28^{\circ} \mathrm{C}$ for $48 \mathrm{~h}$, and subsequently checked for clearing zones around the cultures. E. coli strain DSM 498 was used as a DNase negative control. The ability to metabolize DNA was tested using IF-A indicator medium (BIOLOG GENIII system; Biolog, Hayward, USA) supplemented with $2 \% \mathrm{NaCl}$. The indicator medium was inoculated with the test strain and dispensed into a 96-well plate. Duplicate wells of each strain were supplemented with dNTP's (final concentrations: 99, 291, and $566 \mu \mathrm{M})$, salmon sperm DNA (20, 58, and $\left.113 \mathrm{mg} \mathrm{L}^{-1}\right)$, or marine broth $(0.09 \mathrm{x}$ and $0.18 \mathrm{x})$. Plates were incubated for 7 days at $28^{\circ} \mathrm{C}$ and subsequently checked for purple coloration as indication that the provided substrate had been metabolized.

Mucin as a growth-supporting substrate of ascidian-derived Endozoicomonas isolates and E. elysicola DSM 22380 was tested with an agar-plate-based assay. Marine mucin agar was prepared containing the following $\left(\mathrm{L}^{-1}\right)$ : mucin from porcine stomach (Type II, Sigma-Aldrich; $10 \mathrm{~g})$, ferric citrate (0.1 g), $\mathrm{NaCl}(19.45$ g), $\mathrm{MgCl}_{2}$ (8.8 g), $\mathrm{Na}_{2} \mathrm{SO}_{4}$ (3.24 g), $\mathrm{CaCl}_{2}$ (1.8 g), $\mathrm{KCl}$ (0.55 g), $\mathrm{NaHCO}_{3}(0.16 \mathrm{~g}), \mathrm{KBr}(80 \mathrm{mg}), \mathrm{NH}_{4} \mathrm{NO}_{3},(1.6 \mathrm{mg}), \mathrm{Na}_{2} \mathrm{HPO}_{4}$ $(8 \mathrm{mg})$, agar $(6.0 \mathrm{~g})$. Prior to autoclaving, $\mathrm{pH}$ was adjusted to 7. After autoclaving, the mucin agar medium was cooled down to $45^{\circ} \mathrm{C}$, before adding $1 \mathrm{~mL}$ vitamin (Widdel et al., 1983), $1 \mathrm{~mL}$ vitamin B12 (Widdel et al., 1983), and $2 \mathrm{~mL}$ trace metal SL-10 (Widdel and Bak, 1992) solutions per L. Liquid cultures of the tested strains were spotted on the mucin agar, incubated at $21^{\circ} \mathrm{C}$ for $48 \mathrm{~h}$, and subsequently inspected for growth.

\section{Availability of Sequences and Isolates}

Sequences obtained in this study were deposited at GenBank under the accession numbers KU647816-KU647849 (CO1 sequences of ascidian hosts), KT364255-KT364260 and KU647850-KU647930 (obtained isolates), and KU647931KU648390 (culture-independent screenings). The obtained isolates are available upon request.

\section{RESULTS AND DISCUSSION}

\section{Ascidian Phylogeny}

Phylogenetic analyses overall supported the morphology-based taxonomic identification of the ascidians. Thus all $A$. aspersa CO1 sequences formed a well-supported clade (bootstrap values $>99 \%$ in all analyses, Figure S3). The CO1 sequences of A. scabra obtained in this study formed two separate but well-supported clades (bootstrap values $>84 \%$ ). The first clade grouped A. scabra sequences from the Mediterranean Sea with obtained sequences of juvenile specimens that could not be unambiguously identified by morphology (Ascidiella sp.). The second clade grouped all of the Swedish A. scabra sequences (bootstrap values $>99 \%$ ) and matched A. scabra sequences obtained from Atlantic individuals 
(Nishikawa et al., 2014). All the sequences obtained for the Scandinavian Ascidia sp. formed a single clade (bootstrap values $>99 \%$ ) within the Phlebobranchia. C. intestinalis sequences obtained in this study formed a well-supported clade with other Ciona sequences retrieved from GenBank (bootstrap values $>99 \%$ ), including Ciona robusta (formerly C. intestinalis type A; Brunetti et al., 2015). The confident separation of the $C$. robusta clade and our generated Ciona sequences indicates that the here studied animals were $C$. intestinalis. The last clade comprised all the Stolidobranchia samples analyzed here. All $S$. clava sequences (from this study and GenBank) formed a strongly supported clade (bootstrap values $>99 \%$ ) within the Styela spp. clade. Botryllid ascidians also formed a monophyletic clade, with all $B$. schlosseri sequences grouping together in a well-supported clade (bootstrap values $>96 \%$ ).

\section{Bacteria Associated with Pharynx Tissue of Ascidians}

Rather than characterizing the bacterial diversity associated with pharynges of ascidians, the present study aimed at identifying potentially symbiotic bacteria, indicated by their general and specific association with ascidians, using culture-independent, and -dependent screenings. An initial screening of pharynx samples with general bacteria primers retrieved $16 \mathrm{~S}$ rRNA gene sequences affiliating with genera of the Alphaproteobacteria (genera Hoeflea and Roseobacter), Gammaproteobacteria (Alteromonas, Colwellia, Pseudoalteromonas, Pseudomonas, Vibrio, Neptuniibacter, and Endozoicomonas), Deltaproteobacteria (Halingium), Epsilonproteobacteria (Arcobacter), and Fusobacteria (Psychrilyobacter) from more than one ascidian specimen

TABLE 1 | Identity of ascidian-associated bacteria as detected by $16 \mathrm{~S}$ rRNA gene amplification.

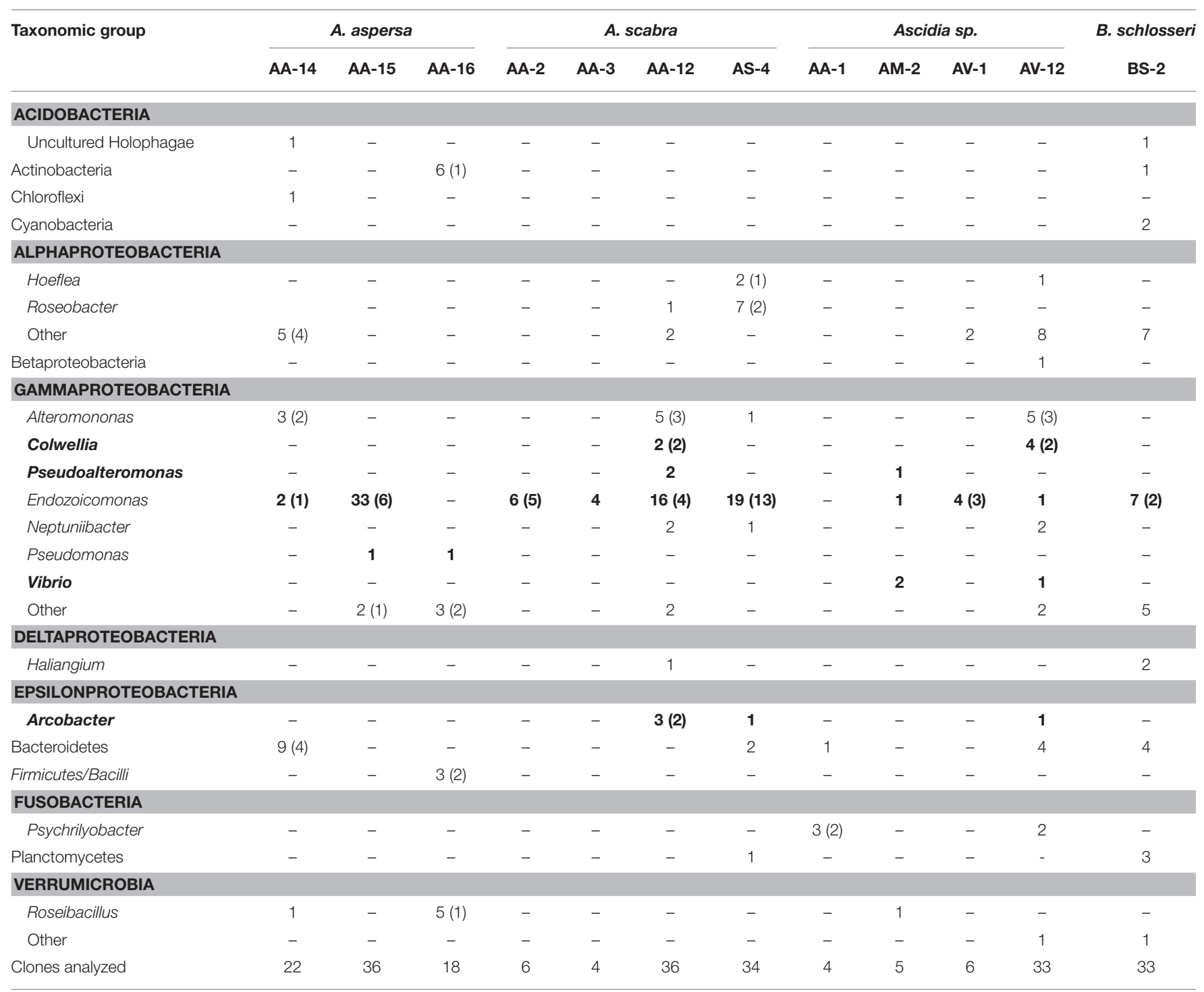

Host specimens are shown with their identifiers. Genera also detected by culturing (Table 2) are shown in bold. Numbers represent the number of obtained clones for a given taxonomic group. Numbers in parentheses represent the number of obtained unique ribotypes ( $>0.5 \%$ sequence divergence) per group. - , no data. 
TABLE 2 | Identity of ascidian-associated bacteria as detected by culturing.

\begin{tabular}{|c|c|c|c|c|c|}
\hline \multirow{2}{*}{$\begin{array}{l}\text { Phylogenetic } \\
\text { affiliation }\end{array}$} & \multirow{2}{*}{$\begin{array}{l}\text { A. aspersa } \\
\text { AS-1 }\end{array}$} & \multirow{2}{*}{$\begin{array}{c}\text { A. scabra } \\
\text { AS-2 }\end{array}$} & \multicolumn{2}{|c|}{ Ascidia sp. } & \multirow{2}{*}{$\begin{array}{c}\text { Ascidiella sp. } \\
\qquad \text { AV-10 }\end{array}$} \\
\hline & & & AM-5 & AV-11 & \\
\hline \multicolumn{6}{|c|}{ ALPHAPROTEOBACTERIA } \\
\hline Tropicibacter & - & - & 1 & - & - \\
\hline \multicolumn{6}{|c|}{ GAMMAPROTEOBACTERIA } \\
\hline Microbulbifer & 3 & - & - & - & 1 \\
\hline Colwellia & - & - & 5 & 1 & - \\
\hline Pseudoalteromonas & - & - & - & 3 & - \\
\hline Shewanella & 1 & - & 6 & 16 & 3 \\
\hline Endozoicomonas & - & 1 & - & - & 13 \\
\hline Photobacterium & 1 & - & 1 & - & 2 \\
\hline Vibrio & - & - & 8 & 7 & - \\
\hline Other & - & - & 6 & - & 1 \\
\hline \multicolumn{6}{|c|}{ EPSILONPROTEOBACTERIA } \\
\hline Arcobacter & 1 & - & 1 & - & - \\
\hline Bacteroidetes & - & - & 1 & - & - \\
\hline Firmicutes/Bacilli & - & - & - & - & 1 \\
\hline Unidentified & - & 14 & - & 7 & - \\
\hline $\begin{array}{l}\text { Total strains } \\
\text { analyzed }\end{array}$ & 6 & 15 & 29 & 34 & 21 \\
\hline
\end{tabular}

Numbers represent the number of obtained isolates for a given taxonomic group. Host specimens are shown with their identifiers. Genera also detected by $16 S$ rRNA gene amplification (Table 1) are shown in bold. -, no data.

(Table 1). Sequences affiliating with the Endozoicomonas genus were retrieved most frequently, and were detected in eight of twelve screened ascidian specimens.

A complementary culture-based screening yielded several strains with similar taxonomic affiliations as those obtained with the culture-independent approach (Table 2). These isolates affiliated with (i) the gammaproteobacterial genera Colwellia, Pseudoalteromonas, Vibrio, and Endozoicomonas, and (ii) the epsilonproteobacterial genus Arcobacter. In addition, several isolates unique to the culturing approach were obtained. These affiliated mostly with the Gammaproteobacteria and included the genera Aliivibrio, Acinetobacter, Microbulbifer, Moritella, Photobacterium, Shewanella, and Sinobacterium. Additionally, two isolates affiliating with the genera Flammeovirga (Bacteroidetes) and Bacillus (Firmicutes), respectively, were uniquely obtained by culturing. The majority of the obtained isolates shared a $16 \mathrm{~S}$ rRNA gene identity of $>97 \%$ with described species (Table S2).

Most of the detected bacteria are known constituents of seawater or marine sediments (Buchan et al., 2005; Zhao et al., 2009; Bowman, 2014; Garcia and Müller, 2014; GomezGil et al., 2014; Lastovica et al., 2014; López-Pérez and Rodriguez-Valera, 2014) and were likely associated with the sampled pharynges due to the ascidians' filter feeding. However, members of the Vibrionaceae (Gomez-Gil et al., 2014) and the genus Endozoicomonas (Kurahashi and Yokota, 2007; Yang et al., 2010; Nishijima et al., 2013; Pike et al., 2013; Hyun et al., 2014; Appolinario et al., 2016) have also been detected in association with other marine animals and thereby may represent bacteria with a more stable association with the sampled ascidians. The genus Endozoicomonas is of special interest as bacteria from this clade are only very rarely detected outside marine animals; only five sequences out of more than 1000 publically available Endozoicomonas 16S rRNA gene sequences originate from a non-marine-animal source (this study; Figure 1). This result and the detection of Endozoicomonas in 12 of the 17 initially screened ascidian specimens (culturing approach: 2/5, culture-independent approach: 10/12) indicated a symbiotic interaction between Endozoicomonas and ascidians, and consequently led us to focus this study on exploring this interaction.

\section{Distribution and Prevalence of Endozoicomonas in Ascidians}

Endozoicomonas have previously been detected in specimens of the ascidians Botrylloides leachi, Botrylloides sp., B. schlosseri, C. intestinalis, C. robusta, Ciona savignyi, Cystodytes dellechiajei, Diazona violacea, Didemnum sp., Eudistoma sp., Phallusia philippinensis, Polyclinella azemai, and Pycnoclavella diminuta (Table 3). Using a newly designed specific PCR assay, we confirmed the presence of Endozoicomonas in C. intestinalis and $B$. schlosseri, and could expand their known host range to include: A. aspersa, A. scabra, S. clava and two Scandinavian Ascidia and Ascidiella species (Table 3). In the present study, a total of 61 ascidian specimens were screened; 54 of these yielded isolates or sufficient PCR product to confirm the presence of Endozoicomonas (Table S4). Among all screened ascidian species to date, Endozoicomonas has been detected in 25 to $100 \%$ of all specimens within a species; Endozoicomonas could be detected in 19 out of 54 host species (Table 3; for full details see Table S3). Overall, our data and analyses suggest that Endozoicomonas is a facultative symbiont of ascidians. Ascidians associated with Endozoicomonas have been detected in the Atlantic, Pacific, the Mediterranean, and Scandinavian waters (Table 3). This supports an earlier study, which suggested a cosmopolitan distribution of Endozoicomonas (Dishaw et al., 2014).

\section{An Ascidian-Specific Endozoicomonas Clade}

Phylogenetic analysis of the Endozoicomonas clade was complicated by the observation that its members can harbor multiple divergent paralogs of the 16S rRNA gene (Figure S2). Even after focusing on the dominant paralog present in public databases (paralog-1 type), the phylogeny of the clade still remains largely unresolved. Phylogenies reconstructed using ML, MP, and BI-approaches were highly divergent as evidenced by relative Robinson-Foulds values (which represent the percentage of splits that are unique to one of the two compared trees) between 0.65 and 0.71 and a highly ambiguous (i.e., multifurcating) consensus phylogeny (Figure 1).

Despite divergent tree topologies, several host-specific subclades were consistently detected (Figure 1; Figures S4-S6). Most relevant to this study and with the exception of one of the two sequences originating from the Mediterranean C. dellechiajei, all ascidian-derived Endozoicomonas nearly 


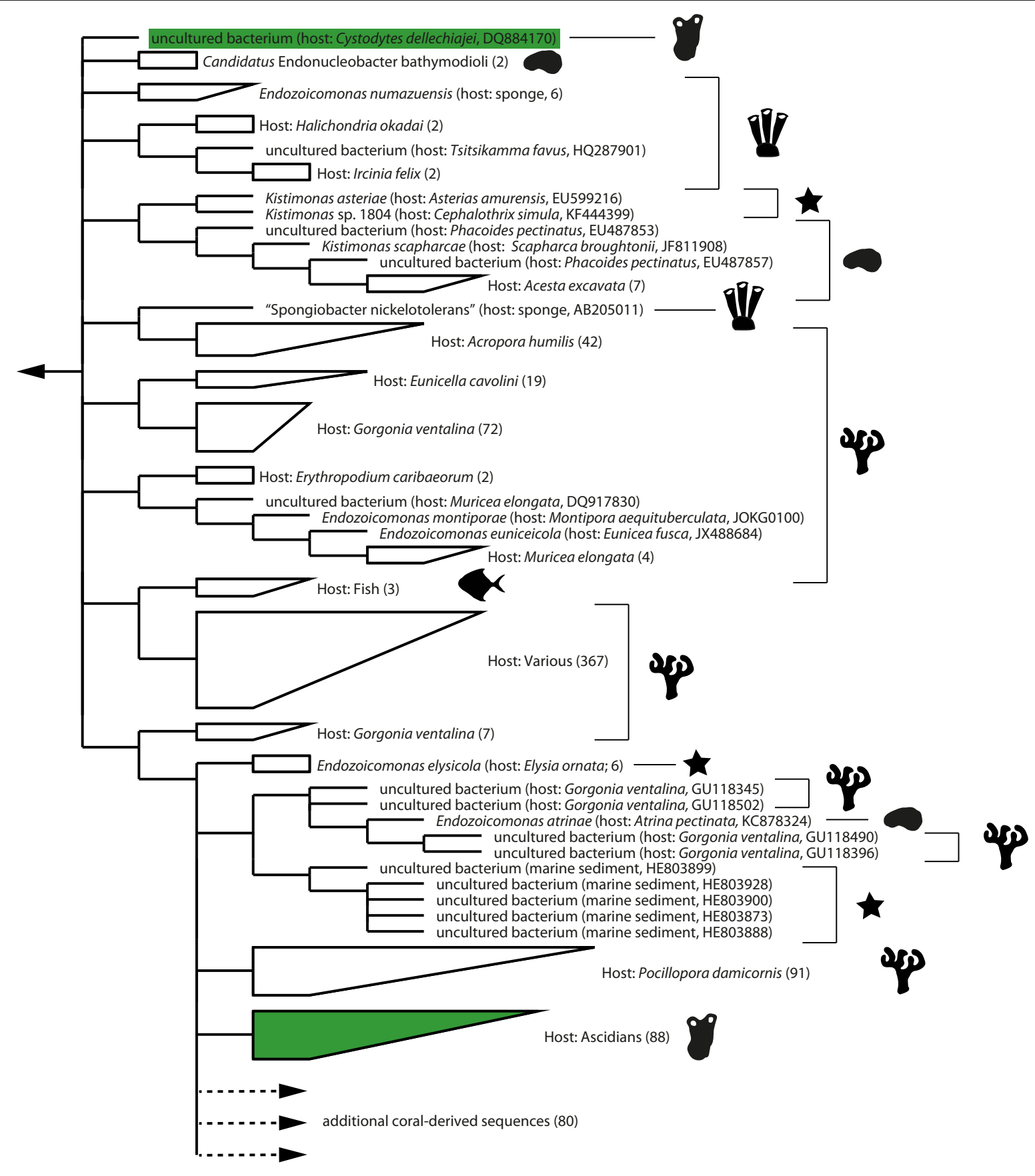

Host group

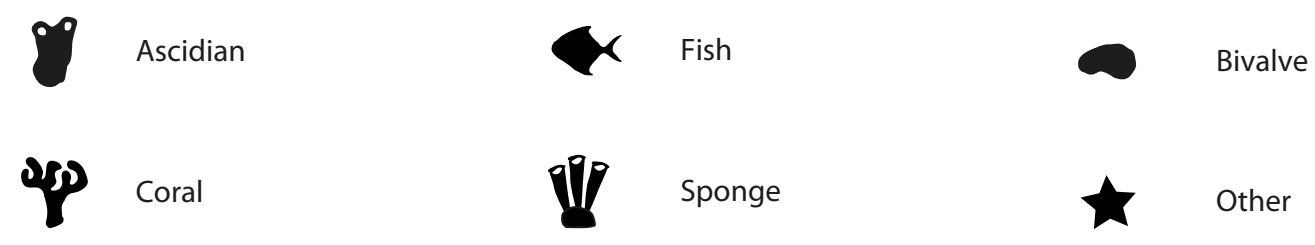

FIGURE 1 | Dendrogram of $16 S$ rRNA gene sequences of the Endozoicomonas clade. Strict consensus representation (i.e., the shown branching patterns and subclades were present in all source trees) of phylogenetic trees calculated by MP, ML, and BI analyses using only nearly full-length ( $\geq 1400$ bp) $16 S$ rRNA gene 


\section{FIGURE 1 | Continued}

sequences. The dendrogram was rooted with sequences of the genera Zooshikella and Hahella (not shown). The dendrogram was truncated (indicated with dotted line and arrow) and does not show an additional 80 sequences of bacteria associated with coral hosts. Host species and accession numbers of single sequences are shown in brackets. For subclades, numbers of containing sequences are shown in brackets. Major host groups are indicated with silhouette symbols. Sequences of ascidian origin are additionally marked with green. Branch lengths do not represent phylogenetic distances.

TABLE 3 | Distribution and prevalence of ascidian-associated Endozoicomonas.

\begin{tabular}{|c|c|c|c|c|c|c|c|c|}
\hline Ascidian host species ${ }^{a}$ & $\begin{array}{l}\text { PCR-based } \\
\text { survey }\end{array}$ & Culturing & $\begin{array}{l}\text { Specific } \\
\text { PCR }\end{array}$ & DGGE & Overall & Overall [\%] & Sampling location & References \\
\hline Ascidia sp. & $3 / 6$ & $0 / 2$ & $7 / 12$ & - & $10 / 20$ & $50 \%$ & Gullmarsfjorden, Sweden & This study \\
\hline Ascidiella aspersa & $2 / 3$ & $0 / 1$ & - & - & $2 / 4$ & $50 \%$ & $\begin{array}{l}\text { Western Mediterranean, } \\
\text { Spain; Gullmarsfjorden, } \\
\text { Sweden }\end{array}$ & This study \\
\hline Ascidiella scabra & $4 / 4$ & $1 / 1$ & $7 / 7$ & - & $12 / 12$ & $100 \%$ & Gullmarsfjorden, Sweden & This study \\
\hline Ascidiella sp. & - & $1 / 1$ & $4 / 4$ & - & $4 / 4^{b}$ & $100 \%$ & Gullmarsfjorden, Sweden & This study \\
\hline Botrylloides leachic & Present & - & - & - & n.a. & n.a. & New Zealand & Cahill et al., 2016 \\
\hline Botrylloides sp. & $1 / 1$ & - & - & - & $1 / 1$ & $100 \%$ & Southern California, USA & Tianero et al., 2014 \\
\hline Botryllus schlosseri & $1 / 1$ & - & $6 / 6$ & - & $6 / 6^{d}$ & $100 \%$ & $\begin{array}{l}\text { Limfjorden, Denmark; } \\
\text { Gullmarsfjorden, Sweden }\end{array}$ & This study \\
\hline Botryllus schlosseric & Present & - & - & - & n.a. & n.a. & New Zealand & Cahill et al., 2016 \\
\hline Ciona intestinalis & $7 / 7$ & - & - & - & $7 / 7$ & $100 \%$ & $\begin{array}{l}\text { Cape Cod, USA; Southern } \\
\text { California, USA; Fusaro } \\
\text { Lake, Italy }\end{array}$ & Dishaw et al., 2014 \\
\hline Ciona intestinalis & $0 / 1$ & - & $3 / 3$ & - & $3 / 4$ & $75 \%$ & Gullmarsfjorden, Sweden & This study \\
\hline Ciona robusta ${ }^{\mathrm{C}}$ & Present & - & - & - & n.a. & n.a. & New Zealand & Cahill et al., 2016 \\
\hline Ciona savignyic & Present & - & - & - & n.a. & n.a. & New Zealand & Cahill et al., 2016 \\
\hline Cystodytes dellechiajeic & Present & - & - & - & n.a. & n.a. & $\begin{array}{l}\text { Western Mediterranean, } \\
\text { Spain }\end{array}$ & Martínez-García et al., 2007 \\
\hline Diazona violacea & - & - & - & $1 / 3$ & $1 / 3$ & $33 \%$ & $\begin{array}{l}\text { Western Mediterranean, } \\
\text { Spain }\end{array}$ & Martínez-García et al., 2010 \\
\hline Didemnum sp. & - & $1 / 1$ & - & - & $1 / 1$ & $100 \%$ & $\begin{array}{l}\text { North coast of São Paulo } \\
\text { state, Brazil }\end{array}$ & Menezes et al., 2010 \\
\hline Didemnum sp. & $4 / 10$ & - & - & - & $4 / 10$ & $40 \%$ & $\begin{array}{l}\text { Southern California, USA; } \\
\text { Papua New Guinea }\end{array}$ & Tianero et al., 2014 \\
\hline Eudistoma sp. & $2 / 2$ & - & - & - & $2 / 2$ & $100 \%$ & Florida Keys, USA & Tianero et al., 2014 \\
\hline Phallusia philippinensis & $1 / 1$ & - & - & - & $1 / 1$ & $100 \%$ & Great Barrier Reef, Australia & Erwin et al., 2014 \\
\hline Polyclinella azemai & - & - & - & $1 / 2$ & $1 / 2$ & $50 \%$ & $\begin{array}{l}\text { Western Mediterranean, } \\
\text { Spain }\end{array}$ & Martínez-García et al., 2010 \\
\hline Pycnoclavella diminuta & $1 / 3$ & - & - & - & $1 / 3$ & $33 \%$ & Great Barrier Reef, Australia & Erwin et al., 2014 \\
\hline Styela clava & - & - & $1 / 4$ & - & $1 / 4$ & $25 \%$ & Limfjorden, Denmark & This study \\
\hline
\end{tabular}

The number of Endozoicomonas-positive specimens relative to all screened specimens is shown for each ascidian species. -, no data; ND, not determined.

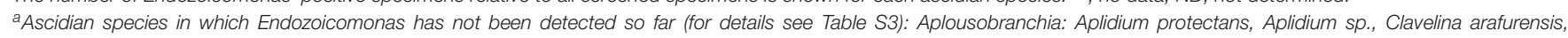
Clavelina meridionalis, Cystodytes sp., Didemnum cf. albopunctatum, Didemnum cf. granulatum, Didemnum fulgens, Didemnum multispirale, Didemnum sp., Eudistoma amplum, Leptoclinides madara, Lissoclinum badium, Lissoclinum bistratum, Lissoclinum cf. caspulatum, Lissoclinum patella, Polycitor giganteus, Pseudodistoma crucigaster, Pycnoclavella sp.,

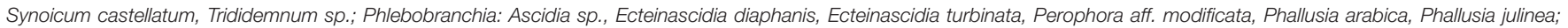
Stolidobranchia: Botrylloides violaceus, Molgula manhattensis, Polycarpa argentata, Polycarpa aurata, Pyura sp., Styela plicata, Styela sp.

bone specimen was screened both by culturing and specific PCR.

${ }^{c}$ Based on the publication, no prevalence data could be inferred.

${ }^{d}$ One specimen was screened both during the PCR-based survey and by specific PCR.

full-length sequences formed a newly defined, ascidian-specific subclade (Figures 1, 2). This subclade contained 88 ascidianderived sequences: eight originating from Baltic Sea Ascidia and Ascidiella species (this study), one originating from a Mediterranean specimen of C. dellechiajei (Martínez-García et al., 2007) and 79 originating from Atlantic and Pacific specimens of C. intestinalis (Dishaw et al., 2014; Figure 2).
Pairwise sequence identities within the subclade were as low as $96.8 \%$ (Table S5); this indicates a clade at the genus level (Yarza et al., 2014) containing different species. The most closely related species to this subclade are Endozoicomonas atrinae (isolated from the intestine of the marine pen shell Atrina pectinata) and Endozoicomonas elysicola (isolated from the marine sea slug Elysia ornata) with sequence identities to 


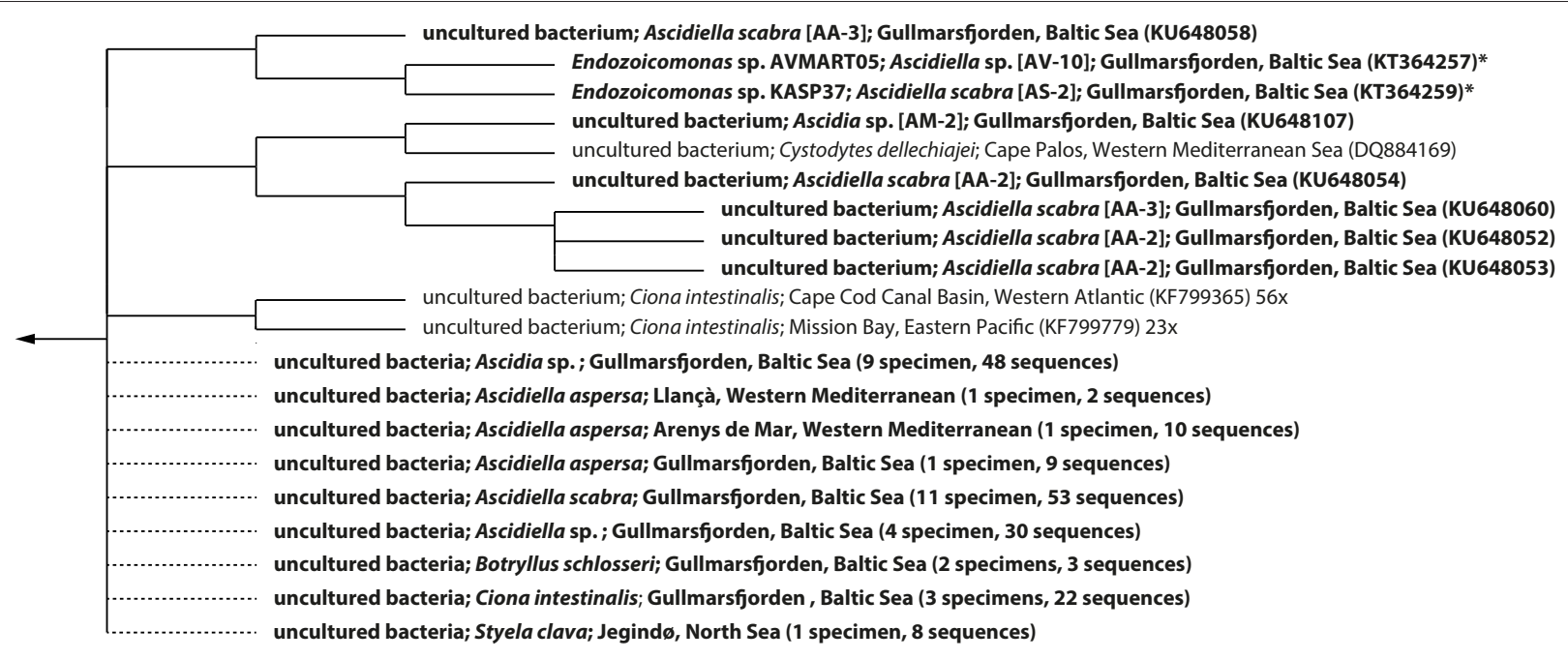

FIGURE 2 | Dendrogram of 16S rRNA gene sequences of Endozoicomonas affiliating with the ascidian-specific subclade depicted in Figure 1. Host species and geographic origin are given for each sequence, followed by the corresponding accession number in brackets. Sequences generated in the present study are shown in bold face. Sequences originating from Endozoicomonas isolates are marked with an asterisk. The dendrogram was truncated and does not show an additional 77 sequences of bacteria associated with Atlantic and Pacific specimens of the ascidian Ciona intestinalis (all from Dishaw et al., 2014). A summary of partial Endozoicomonas sequences generated in this study and confidently assigned to the ascidian-specific subclade was added manually (indicated with dotted lines) to illustrate host and geographic distribution. For these, the number of specimens harboring representatives of the ascidian-specific subclade as well as the total number of positively assigned sequences is shown in brackets (see also Table S6). Branch lengths do not represent phylogenetic distances.

TABLE 4 | Physiological characteristics of Endozoicomonas isolated from ascidians and $E$. elysicola.

\begin{tabular}{|c|c|c|c|}
\hline Physiological property & $\begin{array}{l}\text { Endozoicomonas } \\
\text { sp. AVMART05 }\end{array}$ & $\begin{array}{l}\text { Endozoicomonas } \\
\text { sp. KASP37 }\end{array}$ & E. elysicola \\
\hline Hemolysis & - & - & n.d. \\
\hline $\begin{array}{l}\text { Antibacterial activity: } \\
\text { diffusion assay against } \\
\text { E.coli }\end{array}$ & - & - & n.d. \\
\hline $\begin{array}{l}\text { Antibacterial activity: } \\
\text { diffusion assay against } \\
\text { B. cereus }\end{array}$ & - & - & n.d. \\
\hline $\begin{array}{l}\text { Antibacterial activity: } \\
\text { diffusion assay against } \\
\text { S. epidermidis }\end{array}$ & - & - & n.d. \\
\hline $\begin{array}{l}\text { Antibacterial activity: } \\
\text { overlay assay against E.coli }\end{array}$ & - & - & n.d. \\
\hline $\begin{array}{l}\text { Antibacterial activity: } \\
\text { overlay assay against } B \text {. } \\
\text { cereus }\end{array}$ & - & - & n.d. \\
\hline $\begin{array}{l}\text { Antibacterial activity: } \\
\text { overlay assay against } S \text {. } \\
\text { epidermidis }\end{array}$ & - & - & n.d. \\
\hline DNase activity & + & + & + \\
\hline $\begin{array}{l}\text { Metabolizing of salmon } \\
\text { sperm DNA }\end{array}$ & - & - & n.d. \\
\hline Metabolizing of dNTP's & - & - & n.d. \\
\hline Growth on mucin & + & + & + \\
\hline
\end{tabular}

All data was obtained in the present study. Abbreviations: -, negative; +, positive; n.d., no data.

the ascidian-specific subclade of $96.6-98.1$ and $96.5-98.0 \%$, respectively (Table S5). The majority of generated partial Endozoicomonas $16 \mathrm{~S}$ rRNA gene sequences $(61 \%$; 185 out of
301 sequences) could be confidently assigned to the ascidianspecific subclade (Figure 2; Table S6). However, for sequences obtained from $B$. schlosseri, the only colonial ascidian tested in the present study, overall only $11 \%$ (3 out of 28) of the retrieved Endozoicomonas sequences affiliated with the ascidianspecific subclade (Table S6). Other noteworthy cases include two specimens of Ascidia sp. (specimens AM-5 and AV-12) and two specimens of A. scabra (AA-12 and AS-3), where also the majority of Endozoicomonas sequences (>70\%) did not affiliate with the ascidian-specific subclade (Table S6). This result may suggest a larger diversity of ascidian-associated Endozoicomonas (possibly divided into ascidian specialists and more generalist species), or simply be due to insufficient phylogenetic information.

The current data set is insufficient to explore host-species specificity within the ascidian-specific subclade due to the limited number of nearly full-length 16S rRNA gene sequences of ascidian-derived Endozoicomonas, the limited resolution of the 16S rRNA gene, and the presence of divergent paralogs, which complicates the analysis of environmental sequences. The question of a species-specific symbiosis thus has to await full genome information for multiple ascidian-derived Endozoicomonas strains.

\section{Interaction between Endozoicomonas and Ascidians}

Whether Endozoicomonas are transmitted horizontally or vertically between ascidians is currently not clear. A previous study targeting bacteria associated with the colonial ascidian C. dellechiajei detected the presence of Endozoicomonas in adult specimens but not in larvae (Martínez-García et al., 

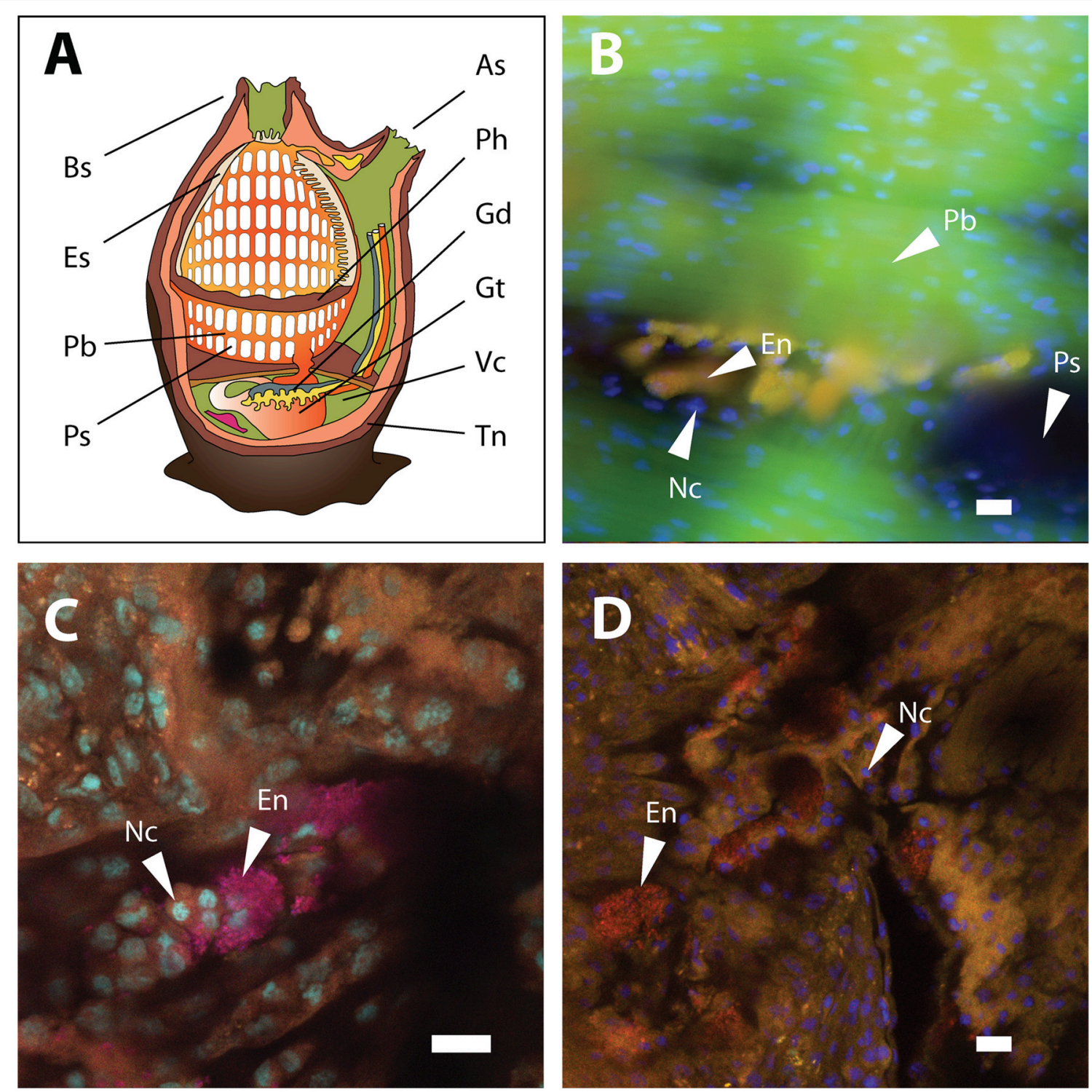

FIGURE 3 | Ascidian anatomy and FISH detection of Endozoicomonas in the pharynx tissue of $\boldsymbol{A}$. aspersa. (A) Anatomical sketch of a solitary ascidian (redrawn from multiple sources). (B) Micrograph of Endozoicomonas microcolonies detected by probe ENDO-1240 (green) and probe mix EUB338 I-III (red). Overlay of the two probes produced the yellow-colored colonies observed in the micrograph. Autofluorescent pharynx tissue is shown in green. (C) Confocal micrograph of pharynx-associated Endozoicomonas microcolonies detected by probe ENDO-580 (red) and probe mix EUB338 I-III (pink). Overlay of the two probes produced the magenta-colored colonies shown in the micrograph. Pharynx nuclei were stained with DAPI (cyan). (D) Confocal micrograph of pharynx-associated Endozoicomonas microcolonies detected by probe ENDO-580 (red). Pharynx nuclei were stained with DAPI (blue). All scale bars, 10 um. As, atrial siphon; Bs, buccal siphon; En, Endozoicomonas microcolonies; Es, endostyle; Gd, gonads; Gt, gut; Nc, nuclei of pharynx tissue; Pb, pharyngeal bars; Ph, pharynx; Ps, pharyngeal stigmata; Tn, tunic; Vc, visceral cavity.

2007). Unfortunately, no ascidian larvae or juveniles could be obtained for the present study. However, the detection of a sequence affiliating with the ascidian-specific subclade in a water sample from the Gullmarsfjord sampling site (accession number: KU648384; this study) suggests dissemination of Endozoicomonas by horizontal transmission.

Endozoicomonas cells were detected in pharynx samples of A. aspersa (Figure 3), A. scabra, and Ascidia sp. (one specimen each) by FISH. Endozoicomonas formed microcolonies on the pharyngal epithelium outside of the host cells. However, due to high background fluorescence of the pharynx tissue, an additional intracellular localization within the host's pharynx cells cannot be excluded. Host cell nuclei and Endozoicomonas microcolonies did never co-localize (Figures 3C,D), rendering an intranuclear localization of Endozoicomonas (as in bathymodiolin mussels) unlikely. These FISH results suggest that Endozoicomonas are not just enriched by the ascidians from seawater by filtration but are actually able to grow in 
situ in their host, where they occupy a protected niche in crevices and grooves of the pharynx. Currently no data exist on the localization of Endozoicomonas in other ascidian species. However, similar bacterial microcolonies, albeit of unknown identity, have previously been reported in association with the pharynx of larvae of the ascidian Ecteinascidia turbinata (Moss et al., 2003). Endozoicomonas associated with the Red Sea coral Stylophora pistillata also grow as microcolonies in the coral endoderm (Bayer et al., 2013), while Endozoicomonas associated with bathymodiolin mussels grow inside cell nuclei of the host (Zielinski et al., 2009). Interestingly, in both ascidians and the coral, Endozoicomonas assumes a smaller cell size (diameter, 1 $\mu \mathrm{m}$ ) and coccoid morphology in situ, compared to the larger rod-shaped cells (cell size up to $0.5 \times 10 \mu \mathrm{m}$ ) of laboratory pure cultures (Kurahashi and Yokota, 2007; Yang et al., 2010; Nishijima et al., 2013; Pike et al., 2013; Hyun et al., 2014; Figure S7, this study), indicating morphological adaptation to the host environment.

Putative interactions between Endozoicomonas and ascidians were investigated based on two Endozoicomonas isolates affiliating with the ascidian-specific subclade; Endozoicomonas sp. AVMART05 and KASP37 (Table 4; Table S2). Theses isolates were obtained from Ascidiella scabra and Ascidiella sp., respectively, on marine agar (containing yeast extract and peptone), and were thus characterized as chemoorganoheterotrophs. Since the intranuclear Endozoicomonas of bathymodiolin mussels were proposed to use the host's chromatin as nutritional source (Zielinski et al., 2009), the possibility of a similar lifestyle was tested for the ascidian-associated Endozoicomonas. In support of the chromatin-feeding hypothesis, both isolates showed the production of extracellular DNase (Table 4). However, the isolates were not able to metabolize high-molecular weight DNA or dNTP's (Table 4). These results and the apparent extracellular localization of ascidian-associated Endozoicomonas indicate a different kind of interaction with the host compared to the intranuclear mussel parasites.

The ascidian-specific Endozoicomonas subclade contains a sequence retrieved from $C$. dellechiajei, an ascidian shown to produce bioactive compounds (Loukaci et al., 2000; LópezLegentil et al., 2005; Bontemps et al., 2010). Based on this and the observation of antibacterial properties of Endozoicomonas isolated from marine sponges (Gram et al., 2010; Flemer et al., 2012; Rua et al., 2014), we hypothesized that Endozoicomonas defend the host against bacterial infections or predators in a mutualistic relationship. In our assays, neither of the two ascidian-derived isolates showed evidence of antibacterial activity, or the production of cytotoxic compounds that could indicate a predator-deterrent role (Lopanik, 2014). As the production of cytotoxins is also a common trait of pathogens (Aktories and Barbieri, 2005), the lack of cytotoxic activity does not support a pathogenic interaction between Endozoicomonas and ascidians either. However, this does not exclude the production of secondary metabolites with functions not assessed here or produced only under in situ conditions, i.e., when associated with the ascidian host.
The majority of described ascidian species are filter feeders that catch their food in a moving mucus layer covering their pharynx that is continuously secreted by the endostyle (MacGinitie, 1939; Bone et al., 2003). The ascidian mucus layer apparently consists of mucopolysaccharides surrounding a protein core and it is currently not known if it is similar across different ascidians (Flood and Fiala-Medioni, 1981; Bone et al., 2003). Both ascidian-derived isolates grew well on porcine mucus glycoproteins (mucin) as substrate (Table 4), indicating that mucus may be an important nutrient source for Endozoicomonas in ascidians. Interestingly, E. elysicola also grew well on mucin, suggesting that this trait may be more widespread among the Endozoicomonas clade.

\section{CONCLUSION}

Based on our combined molecular screening, phylogenetic, FISH, and functional results, ascidian-associated Endozoicomonas appear to form a specific, yet facultative symbiosis with their host. They are likely horizontally transmitted commensals that live off the mucus continuously secreted by the pharynx without affecting the ascidian host. Additionally, based on the observations that the sea-slug-derived E. elysicola also grows on mucin (this study), and that Endozoicomonas symbionts are often found in mucus layers of other hosts (Morrow et al., 2012; Bayer et al., 2013; Carlos et al., 2013; Correa et al., 2013; Vezzulli et al., 2013), we propose that mucus-degradation and metabolism also plays a role in other Endozoicomonas-hosts systems.

\section{AUTHOR CONTRIBUTIONS}

LS and AS jointly designed experiments. LS and AS wrote the manuscript. MO, AS, KK, JJ, and PF collected Swedish ascidians. SL collected Spanish ascidians. LS, JJ, PF, KK, and AS collected Danish ascidians. PF and $\mathrm{MO}$ assisted with ascidian identification and dissection. LS, JJ, and SL generated CO1 gene sequence data. SL performed phylogenetic analysis of ascidian CO1 genes. LS, JJ, KK, and AS generated sequence data of ascidian-associated bacteria. LS and KK isolated ascidian-associated bacteria. LS performed phylogenetic analyses, re-analyses of next generation sequencing data, and physiological tests of Endozoicomonas isolates. LS and JJ designed and tested Endozoicomonas-specific oligonucleotide primers and probes. AS performed fluorescence in situ hybridizations on pharynx sections. All co-authors commented on the manuscript.

\section{FUNDING}

This project was funded by the Danish Council for Independent Research/Natural Sciences (DFF FNU; 09-064111), the Aarhus University Research Foundation (AU Ideas Program 2013; R9-A995-13-S833), the European Community (ASSEMBLE grant agreement no. 227799), the Danish National Research Foundation, and the Max Planck Society. Sampling in Spain was supported by the Spanish Ministry of Economy and 
Competitiveness (MINECO) project MARSYMBIOMICS CTM2013-43287-P.

\section{ACKNOWLEDGMENTS}

We thank Anne Stentebjerg, Susanne Nielsen, Trine Bech Søgaard, Tove Wiegers, and Britta Poulsen for excellent laboratory assistance, and Marie Rosenstand Hansen and the crews of the Sven Lovén Centre for Marine Sciences-Kristineberg

\section{REFERENCES}

Aktories, K., and Barbieri, J. T. (2005). Bacterial cytotoxins: targeting eukaryotic switches. Nat. Rev. Microbiol. 3, 397-410. doi: 10.1038/nrmicro1150

Alm, E. W., Oerther, D. B., Larsen, N., Stahl, D. A., and Raskin, L. (1996). The oligonucleotide probe database. Appl. Environ. Microbiol. 62, 3557-3559.

Appolinario, L. R., Tschoeke, D. A., Rua, C. P., Venas, J. T., Campeão, M. E., Amaral, G. R. S., et al. (2016). Description of Endozoicomonas arenosclerae sp. nov. using a genomic taxonomy approach. Antonie Van Leeuwenhoek 109, 431-8. doi: 10.1007/s10482-016-0649-x

Bayer, T., Neave, M. J., Alsheikh-Hussain, A., Aranda, M., Yum, L. K., Mincer, T., et al. (2013). The microbiome of the Red Sea coral Stylophora pistillata is dominated by tissue-associated Endozoicomonas bacteria. Appl. Environ. Microbiol. 79, 4759-4762. doi: 10.1128/AEM.00695-13

Bone, Q., Carré, C., and Chang, P. (2003). Tunicate feeding filters. J. Mar. Biol. Assoc. U.K. 83, 907-919. doi: 10.1017/S002531540300804Xh

Bontemps, N., Bry, D., López-Legentil, S., Simon-Levert, A., Long, C., and Banaigs, B. (2010). Structures and antimicrobial activities of pyridoacridine alkaloids isolated from different chromotypes of the ascidian Cystodytes dellechiajei. J. Nat. Prod. 73,1044-1048. doi: 10.1021/np900751k

Bowman, J. P. (2014). “The family Colwelliaceae," in The Prokaryotes, eds E. Rosenberg, E. F DeLong, S. Lory, E. Stackebrandt, and F. Thompson (Berlin; Heidelberg: Springer), 179-195.

Brunetti, R., Gissi, C., Pennati, R., Caicci, F., Gasparini, F., and Manni, L. (2015). Morphological evidence that the molecularly determined Ciona intestinalis type A and type B are different species: Ciona robusta and Ciona intestinalis. J. Zool. Syst. Evol. Res. 53, 186-193. doi: 10.1111/jzs.12101

Buchan, A., González, J. M., and Moran, M. A. (2005). Overview of the marine Roseobacter lineage. Appl. Environ. Microbiol. 71, 5665-5677. doi: 10.1128/AEM.71.10.5665-5677.2005

Cahill, P. L., Fidler, A. E., Hopkins, G. A., and Wood, S. A. (2016). Geographically conserved microbiomes of four temperate water tunicates. Environ. Microbiol. Rep. doi: 10.1111/1758-2229.12391. [Epub ahead of print].

Camacho, C., Coulouris, G., Avagyan, V., Ma, N., Papadopoulos, J., Bealer, K., et al. (2009). BLAST+: architecture and applications. BMC Bioinformatics 10:421. doi: $10.1186 / 1471-2105-10-421$

Carlos, C., Torres, T. T., and Ottoboni, L. M. M. (2013). Bacterial communities and species-specific associations with the mucus of Brazilian coral species. Sci. Rep. 3:1624. doi: $10.1038 /$ srep01624

Correa, H., Haltli, B., Duque, C., and Kerr, R. (2013). Bacterial communities of the gorgonian octocoral Pseudopterogorgia elisabethae. Microbiol. Ecol. 66, 972-985. doi: 10.1007/s00248-013-0267-3

Darriba, D., Taboada, G. L., Doallo, R., and Posada, D. (2012). jModelTest 2: more models, new heuristics and parallel computing. Nat. Methods 9, 772-772. doi: 10.1038/nmeth.2109

De Bary, and Anton, H. (1879). Erscheinung der Symbiose. Strassburg: Karl J. Trübner.

Degnan, B. M., Hawkins, C. J., Lavin, M. F., McCaffrey, E. J., Parry, D. L., van den Brenk, A. L., et al. (1989). New cyclic peptides with cytotoxic activity from the ascidian Lissoclinum patella. J. Med. Chem. 32, 1349-1354.

Degnan, P. H., and Ochman, H. (2012). Illumina-based analysis of microbial community diversity. ISME J. 6, 183-194. doi: 10.1038/ismej.2011.74

Dishaw, L. J., Flores-Torres, J., Lax, S., Gemayel, K., Leigh, B., Melillo, D., et al. (2014). The gut of geographically disparate Ciona intestinalis
(Sweden) and of R/V Oscar von Sydow for help during field sampling. We thank Mira Okshevsky for the ascidian illustration in Figure 3.

\section{SUPPLEMENTARY MATERIAL}

The Supplementary Material for this article can be found online at: http://journal.frontiersin.org/article/10.3389/fmicb. 2016.01042 harbors a core microbiota. PLoS ONE 9:e93386. doi: 10.1371/journal.pone.00 93386

Erwin, P. M., López-Legentil, S., and Schuhmann, P. W. (2010). The pharmaceutical value of marine biodiversity for anti-cancer drug discovery. Ecol. Econ. 70, 445-451. doi: 10.1016/j.ecolecon.2010.09.030

Erwin, P. M., Pineda, M. C., Webster, N., Turon, X., and López-Legentil, S. (2012). Small core communities and high variability in bacteria associated with the introduced ascidian Styela plicata. Symbiosis 59, 35-46. doi: 10.1007/s13199012-0204-0

Erwin, P. M., Pineda, M. C., Webster, N., Turon, X., and López-Legentil, S. (2014). Down under the tunic: bacterial biodiversity hotspots and widespread ammonia-oxidizing archaea in coral reef ascidians. ISME J. 8, 575-588. doi: 10.1038 /ismej.2013.188

Faulkner, D. J. (2002). Marine natural products. Nat. Prod. Rep. 19, 1-49. doi: $10.1039 / \mathrm{b} 009029 \mathrm{~h}$

Felsenstein, J. (1985). Confidence limits on phylogenies: an approach using the bootstrap. Evolution 39, 783-791.

Felsenstein, J. (2005). PHYLIP (Phylogeny Inference Package) version 3.6. Seattle, DC: University of Washington, Seattle.

Flemer, B., Kennedy, J., Margassery, L. M., Morrissey, J. P., O'Gara, F., and Dobson, A. D. W. (2012). Diversity and antimicrobial activities of microbes from two Irish marine sponges, Suberites carnosus and Leucosolenia sp. J. Appl. Microbiol. 112, 289-301. doi: 10.1111/j.1365-2672.2011.05211.x

Flood, P. R., and Fiala-Medioni, A. (1981). Ultrastructure and histochemistry of the food trapping mucous film in benthic filter-feeders (ascidians). Acta Zool. 62, 53-65.

Folmer, O., Black, M., Hoeh, W., Lutz, R., and Vrijenhoek, R. (1994). DNA primers for amplification of mitochondrial cytochrome c oxidase subunit I from diverse metazoan invertebrates. Mol. Mar. Biol. Biotechnol. 3, 294-299.

Fu, X., Do, T., Schmitz, F. J., Andrusevich, V., and Engel, M. H. (1998). New cyclic peptides from the ascidian Lissoclinum patella. J. Nat. Prod. 61, 1547-1551.

Fuchs, B. M., Glöckner, F. O., Wulf, J., and Amann, R. (2000). Unlabeled helper oligonucleotides increase the in situ accessibility to 16S rRNA of fluorescently labeled oligonucleotide probes. Appl. Environ. Microbiol. 66, 3603-3607. doi: 10.1128/AEM.66.8.3603-3607.2000

Fuchs, B. M., Pernthaler, J., and Amann, R. (2007). "Single cell identification by fluorescence in situ hybridization," in Methods for General and Molecular Microbiology, 3rd Edn., eds C. A. Reddy, T. J. Beveridge, J. A. Breznak, G. A. Marzluf, T. M. Schmidt and L. R. Snyder (Washington, DC: American Society of Microbiology), 886-896.

Gandhi, V. M., and Cherian, K. M. (2000). Red cell haemolysis test as an in vitro approach for the assessment of toxicity of karanja oil. Toxicol. In Vitro 14 513-516. doi: 10.1016/S0887-2333(00)00046-1

Garcia, R., and Müller, R. (2014). "The family Haliangiaceae," in The Prokaryotes, eds E. Rosenberg, E. F. DeLong, S. Lory, E. Stackebrandt and F. Thompson (Berlin; Heidelberg: Springer), 173-181.

Gomez-Gil, B., Thompson, C. C., Matsumura, Y., Sawabe, T., Iida, T., Christen, R., et al. (2014). "The family Vibrionaceae," in The Prokaryotes, eds E. Rosenberg, E. F. DeLong, S. Lory, E. Stackebrandt and F. Thompson (Berlin; Heidelberg: Springer), 179-195

Gram, L., Melchiorsen, J., and Bruhn, J. B. (2010). Antibacterial activity of marine culturable bacteria collected from a global sampling of ocean surface waters and surface swabs of marine organisms. Mar. Biotechnol. 12, 439-451. doi: 10.1007/s10126-009-9233-y 
Guindon, S., and Gascuel, O. (2003). A simple, fast, and accurate algorithm to estimate large phylogenies by maximum likelihood. Syst. Biol. 52, 696-704. doi: 10.1080/10635150390235520

Hicks, R. E., Amann, R. I., and Stahl, D. A. (1992). Dual staining of natural bacterioplankton with 4',6-diamidino-2-phenylindole and fluorescent oligonucleotide probes targeting kingdom-level 16S rRNA sequences. Appl. Environ. Microbiol. 58, 2158-2163.

Hyun, D. W., Shin, N. R., Kim, M. S., Oh, S. J., Kim, P. S., Whon, T. W., et al. (2014). Endozoicomonas atrinae sp. nov., isolated from the intestine of a comb pen shell Atrina pectinata. Int. J. Syst. Evol. Microbiol. 64, 2312-2318. doi: 10.1099/ijs.0.060780-0

Katoh, K., Kuma, K., Toh, H., and Miyata, T. (2005). MAFFT version 5: improvement in accuracy of multiple sequence alignment. Nucleic Acids Res. 33, 511-518. doi: 10.1093/nar/gki198

Kurahashi, M., and Yokota, A. (2007). Endozoicomonas elysicola gen. nov., sp. nov., a $\gamma$-proteobacterium isolated from the sea slug Elysia ornata. Syst. Appl. Microbiol. 30, 202-206. doi: 10.1016/j.syapm.2006.07.003

Lane, D. J. (1991). "16S/23S rRNA sequencing," in Nucleic Acid Techniques in Bacterial Systematics, eds E. Stackebrandt and M. Goodfellow (Chichester: John Wiley and Sons), 115-175.

Larkin, M. A., Blackshields, G., Brown, N. P., Chenna, R., McGettigan, P. A., McWilliam, H., et al. (2007). Clustal W and Clustal X version 2.0. Bioinformatics 23, 2947-2948. doi: 10.1093/bioinformatics/btm404

Lastovica, A., Stephen, J. L., On, W., and Zhang, L. (2014). "The family Campylobacteraceae," in The Prokaryotes, eds E. Rosenberg, E.F. DeLong, S. Lory, E. Stackebrandt and F. Thompson (Berlin;Heidelberg: Springer), 307-335.

Lewin, R. A. (1981). Prochloron and the theory of symbiogenesis. Ann. N.Y. Acad. Sci. 361, 325-329.

Lopanik, N. B. (2014). Chemical defensive symbioses in the marine environment. Funct. Ecol. 28, 328-340. doi: 10.1111/1365-2435.12160

López-Legentil, S., Dieckmann, R., Bontemps-Subielos, N., Turon, X., and Banaigs, B. (2005). Qualitative variation of alkaloids in color morphs of Cystodytes (Ascidiacea). Biochem. Syst. Ecol. 33, 1107-1119. doi: 10.1016/j.bse.2005. 03.011

López-Legentil, S., Legentil, M. L., Erwin, P. M., and Turon, X. (2015a). Harbor networks as introduction gateways: contrasting distribution patterns of native and introduced ascidians. Biol. Invasions 17, 1623-1638. doi: 10.1007/s10530014-0821-z

López-Legentil, S., Turon, X., Espluga, R., and Erwin, P. M. (2015b). Temporal stability of bacterial symbionts in a temperate ascidian. Front. Microbiol. 6:1022. doi: $10.3389 /$ fmicb. 2015.01022

López-Legentil, S., Turon, X., and Erwin, P.M. (2016). Feeding cessation alters host morphology and bacterial communities in the ascidian Pseudodistoma crucigaster. Front. Zool. 13:2. doi: 10.1186/s12983-016-0134-4

López-Legentil, S., Turon, X., and Schupp, P. (2006). Chemical and physical defenses against predators in Cystodytes (Ascidiacea). J. Exp. Mar. Biol. Ecol. 332, 27-36. doi: 10.1016/j.jembe.2005.11.002

López-Pérez, M., and Rodriguez-Valera, F. (2014). "The family Alteromonadaceae," in The Prokaryotes, eds E. Rosenberg, E. F. DeLong, S. Lory, E. Stackebrandt and F. Thompson (Berlin; Heidelberg: Springer), 69-92.

Loukaci, A., Bultel-Poncé, V., Longeon, A., and Guyot, M. (2000). New lipids from the tunicate Cystodytes cf. dellechiajei, as PLA2 inhibitors. J. Nat. Prod. 63 , 799-802. doi: 10.1021/np990443k

Ludwig, W., Strunk, O., Westram, R., Richter, L., Meier, H., Yadhukumar, et al. (2004). ARB: a software environment for sequence data. Nucleic Acids Res. 32, 1363-1371. doi: 10.1093/nar/gkh293

Lützen, J. G. (1967). Scekdyr. Vol. 75, Danmarks Fauna. Copenhagen: Gads Forlag.

MacGinitie, G. E. (1939). The method of feeding of tunicates. Biol. Bull. 77, 443-447.

Martínez-García, M., Díaz-Valdés, M., and Antón, J. (2010). Diversity of pufM genes, involved in aerobic anoxygenic photosynthesis, in the bacterial communities associated with colonial ascidians. FEMS Microbiol. Ecol. 71, 387-398. doi: 10.1111/j.1574-6941.2009.00816.x

Martínez-García, M., Díaz-Valdés, M., Wanner, G., Ramos-Esplá, A., and Antón, J. (2007). Microbial community associated with the colonial ascidian Cystodytes dellechiajei. Environ. Microbiol. 9, 521-534. doi: 10.1111/j.14622920.2006.01170.x
Menezes, C. B. A., Bonugli-Santos, R. C., Miqueletto, P. B., Passarini, M. R. Z., Silva, C. H. D., Justo, M. R., et al. (2010). Microbial diversity associated with algae, ascidians and sponges from the north coast of São Paulo state, Brazil. Microbiol. Res. 165, 466-482. doi: 10.1016/j.micres.2009.09.005

Morrow, K. M., Moss, A. G., Chadwick, N. E., and Liles, M. R. (2012). Bacterial associates of two caribbean coral species reveal species-specific distribution and geographic variability. Appl. Environ. Microbiol. 78, 6438-6449. doi: 10.1128/AEM.01162-12

Moss, C., Green, D. H., Pérez, B., Velasco, A., Henríquez, R., and McKenzie, J. D. (2003). Intracellular bacteria associated with the ascidian Ecteinascidia turbinata: phylogenetic and in situ hybridisation analysis. Mar. Biol. 143, 99-110. doi: 10.1007/s00227-003-1060-5

Muyzer, G., de Waal, E. C., and Uitterlinden, A. G. (1993). Profiling of complex microbial populations by denaturing gradient gel electrophoresis analysis of polymerase chain reaction-amplified genes coding for $16 \mathrm{~S}$ rRN. Appl. Environ. Microbiol. 59, 695-700.

Muyzer, G., Teske, A., Wirsen, C. O., and, H. W, Jannasch (1995). Phylogenetic relationships of Thiomicrospira species and their identification in deep-sea hydrothermal vent samples by denaturing gradient gel electrophoresis of $16 \mathrm{~S}$ rDNA fragments. Arch. Microbiol. 164, 165-172.

Nicolaisen, M. H., and Ramsing, N. B. (2002). Denaturing gradient gel electrophoresis (DGGE) approaches to study the diversity of ammoniaoxidizing bacteria. J. Microbiol. Methods 50, 189-203. doi: 10.1016/S01677012(02)00026-X

Nishijima, M., Adachi, K., Katsuta, A., Shizuri, Y., and Yamasato, K. (2013). Endozoicomonas numazuensis sp. nov., a gammaproteobacterium isolated from marine sponges, and emended description of the genus Endozoicomonas Kurahashi and Yokota 2007. Int. J. Sys. Evol. Microbiol. 63, 709-714. doi: 10.1099/ijs.0.042077-0

Nishikawa, T., Oohara, I., Saitoh, K., Shigenobu, Y., Hasegawa, N., Kanamori, M., et al. (2014). Molecular and morphological discrimination between an invasive ascidian, Ascidiella aspersa, and its congener A. scabra (Urochordata: Ascidiacea). Zool. Sci. 31, 180-185. doi: 10.2108/zsj.31.180

Ohkuma, M., and Kudo, T. (1998). Phylogenetic analysis of the symbiotic intestinal microflora of the termite Cryptotermes domesticus. FEMS Microbiol. Lett. 164, 389-395.

Paul, V. J., Lindquist, N., and Fenical, W. (1990). Chemical defenses of the tropical ascidian Atapozoa sp. and its nudibranch predators Nembrotha spp. Mar. Ecol. Progr. Ser. 59, 109-118.

Petersen, J. K, and Riisgård, H. U. (1992). Filtration capacity of the ascidian Ciona intestinalis and its grazing impact in a shallow fjord. Mar. Ecol. Progr. Ser. 88, 9-17. doi: 10.3354/meps088009

Pike, R. E., Haltli, B., and Kerr, R. G. (2013). Description of Endozoicomonas euniceicola sp. nov. and Endozoicomonas gorgoniicola sp. nov., bacteria isolated from the octocorals Eunicea fusca and Plexaura sp., and an emended description of the genus Endozoicomonas. Int. J. Syst. Evol. Microbiol. 63, 4294-4302. doi: 10.1099/ijs.0.051490-0

Pruesse, E., Peplies, J., and Glöckner, F. O. (2012). SINA: Accurate high-throughput multiple sequence alignment of ribosomal RNA genes. Bioinformatics 28, 1823-1829. doi: 10.1093/bioinformatics/bts252

Quast, C., Pruesse, E., Yilmaz, P., Gerken, J., Schweer, T., Yarza, P., et al. (2013). The SILVA ribosomal RNA gene database project: improved data processing and web-based tools. Nucleic Acids Res. 41, D590-D596. doi: 10.1093/nar/ gks1219

Robinson, D. F., and Foulds, L. R. (1981). Comparison of phylogenetic trees. Math. Biosci. 53, 131-147.

Ronquist, F., and Huelsenbeck, J. P. (2003). MrBayes 3: Bayesian phylogenetic inference under mixed models. Bioinformatics 19, 1572-1574. doi: 10.1093/bioinformatics/btg180

Rua, C. P. J., Trindade-Silva, A. E., Appolinario, L. R., Venas, T. M., Garcia, G. D., Carvalho, L. S., et al. (2014). Diversity and antimicrobial potential of culturable heterotrophic bacteria associated with the endemic marine sponge Arenosclera brasiliensis. PeerJ. 2:e419. doi: 10.7717/peerj.419

Schliep, K. P. (2011). phangorn: phylogenetic analysis in R. Bioinformatics 27, 592-593. doi: 10.1093/bioinformatics/btq706

Schloss, P. D., Westcott, S. L., Ryabin, T., Hall, J. R., Hartmann, M., Hollister, E. B., et al. (2009). Introducing mothur: open-source, platformindependent, community-supported software for describing and comparing 
microbial communities. Appl. Environ. Microbiol. 75, 7537-7541. doi: 10.1128/AEM.01541-09

Schmidt, E. W., Nelson, J. T., Rasko, D. A., Sudek, S., Eisen, J. A., Haygood, M. G., et al. (2005). Patellamide A and C biosynthesis by a microcin-like pathway in Prochloron didemni, the cyanobacterial symbiont of Lissoclinum patella. Proc. Natl. Acad. Sci. U.S.A. 102, 7315-7320. doi: 10.1073/pnas.0501424102

Schmieder, R., and Edwards, R. (2011). Quality control and preprocessing of metagenomic datasets. Bioinformatics 27, 863-864. doi: 10.1093/bioinformatics/btr026

Schuett, C., Doepke, H., Groepler, W., and Wichels, A. (2005). Diversity of intratunical bacteria in the tunic matrix of the colonial ascidian Diplosoma migrans. Helgol. Mar. Res. 59, 136-140. doi: 10.1007/s10152-004-0212-4

Simmons, T. L., Andrianasolo, E., McPhail, K., Flatt, P., and Gerwick, W. H. (2005). Marine natural products as anticancer drugs. Mol. Cancer Ther. 4, 333-342.

Smith, P. B., Hancock, G. A., and Rhoden, D. L. (1969). Improved medium for detecting deoxyribonuclease-producing bacteria. Appl. Microbiol. 18, 991-993.

Stamatakis, A., Hoover, P., and Rougemont, J. (2008). A rapid bootstrap algorithm for the RAxML web servers. Syst. Biol. 57, 758-771. doi: $10.1080 / 10635150802429642$

Tait, E., Carman, M., and Sievert, S. M. (2007). Phylogenetic diversity of bacteria associated with ascidians in Eel Pond (Woods Hole, Massachusetts, USA). J. Exp. Mar. Biol. Ecol. 342, 138-146. doi: 10.1016/j.jembe.2006.10.024

Tamura, K., Peterson, D., Peterson, N., Stecher, G., Nei, M., and Kumar, S. (2011). MEGA5: Molecular evolutionary genetics analysis using maximum likelihood, evolutionary distance, and maximum parsimony methods. Mol. Biol. Evol. 28, 2731-2739. doi: 10.1093/molbev/msr121

Tavaré, S. (1986). "Some probabilistic and statistical problems in the analysis of DNA sequences," in Lectures on Mathematics in the Life Sciences, Vol. 17: Some Mathematical Questions in Biology - DNA Sequence Analysis, ed R. M. Miura (Providence: American Mathematical Society), 57-86.

Tianero, M. D. B., Kwan, J. C., Wyche, T. P., Presson, A. P., Koch, M., Barrows, L. R., et al. (2014). Species specificity of symbiosis and secondary metabolism in ascidians. ISME J. 9, 615-628. doi: 10.1038/ismej.2014.152

Turon, X. (1987). Ascidians from the Shores of Catalonia and Balearic Islands. Ph.D. dissertation, University of Barcelona, Barcelona.

Vervoort, H. C. R., Pawlik, J., and Fenical, W. (1998). Chemical defense of the Caribbean ascidian Didemnum conchyliatum. Mar. Ecol. Prog. Ser. 164, 221-228.

Vezzulli, L., Pezzati, E., Huete-Stauffer, C., Pruzzo, C., and Cerrano, C. (2013). $16 S$ rDNA pyrosequencing of the Mediterranean gorgonian Paramuricea clavata reveals a link among alterations in bacterial holobiont members, anthropogenic influence and disease outbreaks. PLOS ONE 8:e67745. doi: 10.1371/journal.pone.0067745

Wang, Q., Garrity, G. M., Tiedje, J. M., and Cole, J. R. (2007). Naïve Bayesian classifier for rapid assignment of rRNA sequences into the new bacterial taxonomy. Appl. Environ. Microbiol. 73, 5261-5267. doi: 10.1128/AEM. 00062-07

Widdel, F., and Bak, F. (1992). "Gram-negative mesophilic sulfate-reducing bacteria," in The Prokaryotes, eds A. Balows, H. G. Trüper, M. Dworkin, W. Harder and K. H. Schleifer (New York, NY: Springer), 3352-3378.

Widdel, F., Kohring, G. W., and Mayer, F. (1983). Studies on dissimilatory sulfate-reducing bacteria that decompose fatty acids. Arch. Microbiol. 134, 286-294.

Yang, C. S., Chen, M. H., Arun, A. B., Chen, C. A., Wang, J. T., and Chen, W. M. (2010). Endozoicomonas montiporae sp. nov., isolated from the encrusting pore coral Montipora aequituberculata. Int. J. Syst. Evol. Microbiol. 60, 1158-1162. doi: 10.1099/ijs.0.014357-0

Yang, Z. (1994). Maximum likelihood phylogenetic estimation from DNA sequences with variable rates over sites: approximate methods. J. Mol. Evol. 39, 306-314.

Yang, Z. (1996). Among-site rate variation and its impact on phylogenetic analyses. Trends Ecol. Evol. 11, 367-372.

Yarza, P., Richter, M., Peplies, J., Euzeby, J., Amann, R., Schleifer, K. -H., et al. (2008). The All-Species Living Tree project: A 16S rRNA-based phylogenetic tree of all sequenced type strains. Syst. Appl. Microbiol. 31, 241-250. doi: 10.1016/j.syapm.2008.07.001

Yarza, P., Yilmaz, P., Pruesse, E., Glockner, F. O., Ludwig, W., Schleifer, K. H., et al. (2014). Uniting the classification of cultured and uncultured bacteria and archaea using 16S rRNA gene sequences. Nat. Rev. Microbiol. 12, 635-645. doi: $10.1038 /$ nrmicro3330

Zhao, J. S., Manno, D., and Hawari, J. (2009). Psychrilyobacter atlanticus gen. nov., sp. nov., a marine member of the phylum Fusobacteria that produces $\mathrm{H} 2$ and degrades nitramine explosives under low temperature conditions. Int. J. Syst. Evol. Microbiol.59, 491-497. doi: 10.1099/ijs.0.65263-0

Zielinski, F. U., Pernthaler, A., Duperron, S., Raggi, L., Giere, O., et al. (2009). Widespread occurrence of an intranuclear bacterial parasite in vent and seep bathymodiolin mussels. Environ. Microbiol. 11, 1150-1167. doi: 10.1111/j.14622920.2008.01847.x

Conflict of Interest Statement: The authors declare that the research was conducted in the absence of any commercial or financial relationships that could be construed as a potential conflict of interest.

Copyright ๑ 2016 Schreiber, Kjeldsen, Funch, Jensen, Obst, López-Legentil and Schramm. This is an open-access article distributed under the terms of the Creative Commons Attribution License (CC BY). The use, distribution or reproduction in other forums is permitted, provided the original author(s) or licensor are credited and that the original publication in this journal is cited, in accordance with accepted academic practice. No use, distribution or reproduction is permitted which does not comply with these terms. 